A programação da produção em fundições de pequeno porte: modelagem matemática $\mathrm{e}$ métodos de solução

Claudia Fink 


\section{A programação da produção em fundições de pequeno porte: modelagem matemática e métodos de solução ${ }^{1}$}

Claudia Fink

Orientador: Prof. Dr. Marcos Nereu Arenales

Dissertação apresentada ao Instituto de Ciências Matemáticas e de Computação - ICMC-USP, como parte dos requisitos para obtenção do título de Mestre em Ciências de Computação e Matemática Computacional.

USP - São Carlos

Março/2007

\footnotetext{
${ }^{1}$ Este trabalho contou com o apoio financeiro do $\mathrm{CNPq}$
} 
Aos meus pais

Olávio e Maria 


\section{Agradecimentos}

A Deus por sua fiel companhia.

Ao meu orientador Marcos Nereu Arenales pelos seus ensinamentos, paciência e constante apoio durante esta pesquisa.

Aos meus pais Olávio e Maria Fink e minha irmã Neusa pelo carinho, amor e todas as oportunidades proporcionadas. Muito obrigada. Amo muito vocês.

A todos os meus amigos. Aos de infância, colégio e graduação pelo apoio e amizade constantes. Aos de dança pelos muitos momentos de descontração. Aos do laboratório pelos momentos de estudo e pela alegria sempre presente. Ao casal Diogo e Elisandra pela acolhida, viajens e boas conversas. A dona Hilda e todas as meninas, Ester, Fabiana, Vanessa, Scheila, Deise, Madalena, Monique, Hérica, Gabriela e Laís pelo companheirismo e inesquecível período em que moramos juntas.

Aos professores e funcionários do ICMC que, direta ou indiretamente contribuíram para a realização deste trabalho.

Ao $\mathrm{CNPq}$ pelo apoio financeiro. 


\section{Resumo}

Este trabalho trata de um problema de programação da produção em fundições de pequeno porte, que consiste em programar as ligas que devem ser produzidas em cada período do planejamento e como tais ligas devem ser usadas para a produção de itens sob encomenda, de modo que atrasos e custos operacionais sejam minimizados. Devido à certa incerteza nos dados do problema, a estratégia de horizonte rolante foi empregada. Este problema é representado por um modelo matemático de programação linear inteira mista. Neste trabalho foi desenvolvida uma heurística do tipo residual para obter uma boa solução inteira factível do problema, partindo da solução contínua encontrada pelos métodos relaxe-e-fixe e busca local.

Palavras-chave: Problemas de dimensionamento de lotes, programação inteira mista, programação da produção em fundições. 


\section{Abstract}

This work addresses a planning production problem that arises in small market-driven foundries, which consists of programming a number of alloys that have to be produced in each period of the planning horizon and how these alloys should be used to producing ordered items, in such way that delays and operational costs are minimized. Due to uncertainties in the problem data, the strategy of rolling horizon was used. This problem is modeled as a mixed integer linear programe. In this work we developed a residual typed heuristic in order to obtain a good feasible integer solution of the problem, which are built from the continuous solution found by relax-and-fix and local search methods. Keywords: Lot-sizing problems, mixed integer linear programming, production planning in foundries. 


\section{Conteúdo}

1 Introdução 1

2 Revisão bibliográfica 3

2.1 Problemas de dimensionamento de lotes . . . . . . . . . . . . . . . . 3

2.1.1 Problemas de dimensionamento de lotes monoestágio . . . . . . . . 4

2.1.2 Problemas de dimensionamento de lotes multiestágio . . . . . . . . 9

2.2 O Setor de fundições . . . . . . . . . . . . . . . . . . . . . 11

2.2.1 Uma fundição de pequeno porte . . . . . . . . . . . . . . . . . 15

3 Uma heurística baseada na decomposição do problema 19

3.1 Modelo matemático completo . . . . . . . . . . . . . . . 19

3.2 Decomposição do modelo completo . . . . . . . . . . . . . . . 20

3.2.1 Planejamento da produção das ligas . . . . . . . . . . . . . . . . 20

3.2.2 Planejamento da produção dos itens . . . . . . . . . . . . . . 23

3.3 Heurística para o problema decomposto . . . . . . . . . . . . 24

3.3.1 Heurística lagrangiana para o modelo das ligas . . . . . . . . . . . 24

3.3.2 Heurística lagrangiana para o modelo dos itens . . . . . . . . . . . . 27

4 Modelo de horizonte rolante e estratégias de solução 29

4.1 Modelo de horizonte rolante . . . . . . . . . . . . . . . . . . 32

4.2 Método relaxe-e-fixe . . . . . . . . . . . . . . . . . . 34

4.3 Busca local . . . . . . . . . . . . . . . . . . . . . 35

$\begin{array}{lll}5 & \text { Heurísticas de arredondamento } & 37\end{array}$

5.1 Problema de corte de estoque unidimensional . . . . . . . . . . . . . 37 
5.2 Heurísticas residuais . . . . . . . . . . . . . . . . . . . . . 39

6 Modelo e método de solução proposto 41

6.1 Modelo de horizonte rolante para um PDL monoestágio . . . . . . . . . . . 41

6.2 Método de solução para HR . . . . . . . . . . . . . . . . . . . 43

6.3 Extensão da abordagem proposta . . . . . . . . . . . . . . . . . . . . . . . 49

$\begin{array}{lll}7 & \text { Experimentos computacionais } & 51\end{array}$

7.1 Geração dos dados . . . . . . . . . . . . . . . . . . . . . . . 51

7.2 Resultados computacionais . . . . . . . . . . . . . . . 52

8 Conclusões e trabalhos futuros $\quad 60$

$\begin{array}{ll}\text { Referências bibliográficas } & 61\end{array}$ 


\section{Capítulo 1}

\section{Introdução}

A ABIFA - Associação Brasileira de Fundições (2007) apresenta um balanço positivo do ano de 2006. Conforme os resultados do primeiro semestre, o setor de fundição deve manter a previsão de crescimento em torno dos $5 \%$ divulgada no início deste mesmo ano, chegando a uma produção recorde de 3 milhões de toneladas. De janeiro a junho foram produzidas 1.557.298 toneladas, contra 1.471.019 do mesmo período de 2005, o que representa um incremento de 5,9\%. Na produção regional, São Paulo continua liderando o ranking com 104.626 toneladas em junho de 2006. Logo a seguir vem a região Sul do país com 72.581 toneladas e a região Centro/MG com 68.092 toneladas.

Das indústrias que compõem o setor, a grande maioria é constituida por empresas nacionais de pequeno e médio porte. Nas fundições de grande porte estão incluidas as fundições cativas que, em geral, operam principalmente ligadas ao setor automobilístico. A indústria de fundição é também uma grande empregadora, atualmente emprega em torno de 58 mil trabalhadores, diretamente.

Com o aumento do volume de produção registrado nos últimos dez anos, as necessidades de matérias-primas, mão-de-obra e equipamentos também cresceram, levando a um aumento do quadro de funcionários e dos volumes de compra. Assim, o processo produtivo, que consiste em converter a matéria-prima em produto final, deve ser bem gerenciado.

O gerenciamento da produção de uma empresa, consiste no planejamento e controle da produção, baseado na tomada de decisões para longo, médio e curto prazos, designados 
como, planejamento estratégico, planejamento tático e planejamento operacional, respectivamente.

Este trabalho discute as decisões tático-operacionais no setor de fundições, para empresas de pequeno porte. Para tanto, é utilizado um problema de dimensionamento de lotes, que consiste em planejar as quantidades de itens a serem produzidas em várias (ou única) máquinas em cada período ao longo de um horizonte de tempo finito, de modo a atender uma certa demanda e otimizar uma função objetivo.

O estudo a ser realizado nesta dissertação é baseado em um modelo de dimensionamento de lotes monoestágio de Araújo et al. (2006). Esse modelo de programação inteira mista tem como principal objetivo minimizar o atraso na entrega dos pedidos.

Em Araújo (2003) é aplicada uma estratégia de horizonte rolante em conjunto com um método de busca local para a determinação das variáveis binárias que determinam quais ligas são produzidas no primeiro período de planejamento. Entretanto, um método de otimização inteira é necessário para determinar o número de itens a serem produzidos, e o autor usa um pacote comercial.

Este trabalho consiste em propor procedimentos para o arredondamento da solução contínua (obtida por relaxação linear), inspirados nas heurísticas aplicadas ao problema de corte de estoque estudadas por Poldi (2003), e assim obter soluções inteiras.

Uma breve revisão sobre os problemas de dimensionamento de lotes e o setor de fundições é apresentada no capítulo 2. No capítulo 3, é discutida uma abordagem heurística aplicada num modelo de planejamento da produção de ligas e no modelo de planejamento da produção dos itens. Outro método de solução para o planejamento da produção numa fundição de pequeno porte é apresentada no capítulo 4, e discute um modelo de horizonte rolante, com estratégia de busca local e relaxe-e-fixe. No capítulo 5, são discutidos alguns conceitos do problema de corte de estoque unidimensional e as principais idéias de heurísticas para determinação de soluções inteiras. O modelo e o método de solução propostos neste trabalho são descritos no capítulo 6. No capítulo 7 são apresentados os testes computacionais realizados e, por fim, no capítulo 8, são discutidas as conclusões e propostas futuras. 


\section{Capítulo 2}

\section{Revisão bibliográfica}

\subsection{Problemas de dimensionamento de lotes}

O problema de dimensionamento de lotes busca determinar a quantidade de itens a ser produzida por uma ou mais máquinas em cada período, durante um intervalo de tempo (horizonte de planejamento) finito, de modo a atender uma certa demanda, tendo como objetivo otimizar uma função, como por exemplo, minimizar os custos. Diferentes características práticas levam a uma diversidade de problemas de dimensionamento de lotes.

Nos primeiros estudos de problemas de dimensionamento de lotes, Economic Order Quantity modelo de Harris (1913), foram modelados problemas considerando um item, demanda estacionária, períodos de tempo contínuos e horizonte de planejamento infinito. Não foram considerados restrições de capacidade.

Em 1950, surgiu o Economic Lot Scheduling Problem, com restrições de capacidade e vários itens, demanda estacionária, períodos de tempo contínuos e horizonte de planejamento infinito.

Wagner e Whitin (1958) consideraram a demanda dinâmica, problema monoestágio sem restrição de capacidade, com custo de preparação e um único item. Este modelo considera um horizonte de planejamento finito dividido em vários períodos discretos.

Atualmente, os estudos visam modelos com vários itens, demanda dinâmica e restrições de capacidade. Estes problemas de dimensionamento de lotes podem ser classificados em dois grupos básicos: o monoestágio e o multiestágio. No problema dito monoestágio, nenhum item depende de outro para ser produzido, ou seja, itens indepen- 
dentes. Em um problema multiestágio, para que se produza um certo item é necessário que já tenham sido produzidos outros itens, os componentes, neste caso os itens são ditos dependentes.

O problema em foco neste projeto de pesquisa é, em essência, 2-estágios, pois a produção da liga (componente) deve ser programada para a produção dos itens finais. Entretanto, o problema se aproxima de um monoestágio, já que a decisão de produzir uma liga é modelada por uma variável binária, e não por um lote de produção

\subsubsection{Problemas de dimensionamento de lotes monoestágio}

O problema de dimensionamento de lotes monoestágio, quando são considerados o tempo e o custo de produção, é escrito como um problema de otimização linear inteira (discreta) e a resolução exata do modelo é um problema NP-completo (Maes et al., 1991). No caso em que não são considerados o tempo e o custo de produção, estes problemas recaem em modelos de otimização linear, portanto problemas polinomiais.

Na seqüencia, são apresentados três modelos de problemas de dimensionamento de lotes monoestágios, todos considerando tempo ou custo de preparação.

\section{a) Problema de dimensionamento de lotes monoestágio para um único item sem restrições de capacidade.}

Considere os seguintes dados:

Índice:

$t=1, \ldots, T:$ períodos de tempo.

Dados do problema:

$c_{t}$ : custo unitário de produção no período $t$;

$S_{t}: \quad$ custo de preparação para a produção no período $t ;$

$H_{t}$ : custo unitário de estocagem no período $t$;

$d_{t}:$ demanda do período $t$;

$G$ : número grande. 
Variáveis do problema:

$X_{t}$ : unidades produzidas no período $t$

$I_{t}: \quad$ unidades estocadas no período $t$;

$Y_{t}$ : $\quad$ variável binária, indicando a produção ou não no período $t$.

Formulação do problema:

Minimizar

$$
\sum_{t=1}^{T}\left(H_{t} I_{t}+c_{t} X_{t}+S_{t} Y_{t}\right)
$$

Sujeito a:

$$
\begin{array}{cc}
I_{t-1}+X_{t}-I_{t}=d_{t} & t=1, \ldots, T \\
Y_{t}-G Y_{t} \leq 0 & t=1, \ldots, T \\
1, \text { se } X_{t}>0 & t=1, \ldots, T \\
0, \text { caso contrário } & t=1, \ldots, T . \\
X_{t} \geq 0 \text { e } I_{t} \geq 0 & t
\end{array}
$$

Nesta formulação encontrada em Brahimi et al. (2006), a função objetivo (2.1) minimiza a soma dos custos de estoque, produção e preparação. As restrições (2.2) representam o balanceamento do estoque, ou seja, a quantidade produzida adicionada ao estoque do período anterior deve ser igual à demanda mais a quantidade de itens que sobrar no estoque para o próximo período. As restrições (2.3) e (2.4) asseguram que o custo de preparação é considerado apenas quando existe produção. As restrições (2.5) garantem a não negatividade das variáveis e, particularmente, a não negatividade da variável de estoque garante que a demanda deve ser aceita. O estoque final e inicial são nulos.

Este tipo de problema, embora bastante simplificado, pode auxiliar na resolução de problemas mais complexos. Um exemplo é o problema de dimensionamento de lotes monoestágio com restrições de capacidade que pode ser decomposto em vários subproblemas de dimensionamento de lotes monoestágio para um único item sem restrição de capacidade. Isso é possível ao ser aplicada a relaxação lagrangiana nas restrições de capacidade.

Caso sejam permitidos atrasos no atendimento da demanda pode-se considerar o seguinte modelo (Brahimi et al.(2006), Araújo (2003)): 
Minimizar

$$
\sum_{t=1}^{T}\left(H_{t}^{+} I_{t}^{+}+H_{t}^{-} I_{t}^{-}+c_{t} X_{t}+S_{t} Y_{t}\right)
$$

Sujeito a:

$$
\begin{aligned}
& I_{t-1}^{+}-I_{t-1}^{-}+X_{t}-I_{t}^{+}+I_{t}^{-}=d_{t} \quad t=1, \ldots, T \\
& X_{t}-G Y_{t} \leq 0 \quad t=1, \ldots, T \\
& Y_{t}=\left\{\begin{array}{ll}
1, & \text { se } X_{t}>0 \\
0, & \text { caso contrário }
\end{array} \quad t=1, \ldots, T\right. \\
& X_{t} \geq 0 \text { e } I_{t}^{+}, I_{t}^{-} \geq 0 \quad t=1, \ldots, T .
\end{aligned}
$$

em que:

$I_{t}^{+}: \quad$ unidades estocadas no período $t ;$

$I_{t}^{-}: \quad$ unidades atrasadas no período $t$;

$H_{t}^{+}$: custo unitário de estocagem no período $t$;

$H_{t}^{-}$: custo unitário por atraso no período $t$.

O modelo (2.6)-(2.10) pode ser obtido diretamente de (2.1)-(2.5) com $I_{t}$ livre e $I_{t}=I_{t}^{+}-I_{t}^{-}, \operatorname{com} I_{t}^{+} \geq 0, I_{t}^{-} \geq 0$ e diferentes pesos na função objetivo caso o estoque seja positivo ou negativo.

\section{b) Problema de dimensionamento de lotes monoestágio para um único item} com restrições de capacidade.

É necessário apenas acrescentar a restrição de capacidade:

$$
b_{t} X_{t}+s_{t} Y_{t} \leq \operatorname{cap}_{t} \quad t=1, \ldots, T
$$

ao modelo (2.1)-(2.5), sendo:

$b_{t}: \quad$ tempo necessário para produzir uma unidade no período $t$;

$s_{t}$ : $\quad$ tempo de preparação para a produção no período $t$;

$\operatorname{cap}_{t}$ : limite de capacidade (em unidades de tempo) no período $t$.

Formulação do problema: 
Minimizar

$$
\sum_{t=1}^{T}\left(H_{t} I_{t}+c_{t} X_{t}+S_{t} Y_{t}\right)
$$

Sujeito a:

$$
\begin{aligned}
& I_{t-1}+X_{t}-I_{t}=d_{t} \quad t=1, \ldots, T \\
& b_{t} X_{t}+s_{t} Y_{t} \leq \operatorname{cap}_{t} \quad t=1, \ldots, T \\
& X_{t}-G Y_{t} \leq 0 \quad t=1, \ldots, T \\
& Y_{t}=\left\{\begin{array}{ll}
1, & \text { se } X_{t}>0 \\
0, & \text { caso contrário }
\end{array} \quad t=1, \ldots, T\right. \\
& X_{t} \geq 0 \text { e } I_{t} \geq 0 \quad t=1, \ldots, T \text {. }
\end{aligned}
$$

\section{c) Problema de dimensionamento de lotes monoestágio com multi-itens e res- trições de capacidade.}

No modelo apresentado na sequência, de Trigeiro et al. (1989), é considerado o custo de preparação, a demanda é conhecida em cada período do horizonte de planejamento e a capacidade disponível é limitada.

Neste e nos outros modelos apresentados, o lead time é considerado nulo. Lead time é o tempo mínimo necessário a partir da ordem de produção até que o pedido esteja pronto.

Os seguintes dados são utilizados no problema:

Índices:

$t=1, \ldots, T:$ períodos de tempo;

$i=1, \ldots, N:$ itens.

Dados do problema:

$c_{i, t}: \quad$ custo unitário de produção do item $i$ no período $t$;

$S_{i, t}: \quad$ custo de preparação para a produção do item $i$ no período $t$;

$H_{i, t}$ : custo unitário de estocagem do item $i$ no final do período $t$;

$b_{i}$ : $\quad$ tempo necessário para produzir uma unidade do item $i$;

$s_{i}: \quad$ tempo de preparação para a produção do item $i$; 
$\operatorname{cap}_{t}$ : limite de capacidade (em unidades de tempo) no período $t$;

$d_{i, t}: \quad$ demanda do item $i$ no período $t$;

$G$ : número grande.

Variáveis do problema:

$X_{i, t}$ : $\quad$ unidades do item $i$ produzidas no período $t$;

$I_{i, t}$ : unidades estocadas do item $i$ no final do período $t$;

$Y_{i, t}$ : $\quad$ variável binária que indica se a máquina foi preparada para produzir o item $i$ no período $t$.

Formulação do problema:

Minimizar

$$
\sum_{t=1}^{T} \sum_{i=1}^{N}\left(H_{i, t} I_{i, t}+c_{i, t} X_{i, t}+S_{i, t} Y_{i, t}\right)
$$

Sujeito a:

$$
\begin{array}{cl}
I_{i, t-1}+X_{i, t}-I_{i, t}=d_{i, t} & i=1, \ldots, N \text { e } t=1, \ldots, T \\
\sum_{i=1}^{N} b_{i} X_{i, t}+\sum_{i=1}^{N} s_{i} Y_{i, t} \leq c a p_{t} & t=1, \ldots, T \\
X_{i, t}-G Y_{i, t} \leq 0 & i=1, \ldots, N \text { e } t=1, \ldots, T \\
Y_{i, t} \in\{0,1\} & i=1, \ldots, N \text { e } t=1, \ldots, T \\
X_{i, t} \geq 0 \text { e } I_{i, t} \geq 0 \quad\left(I_{i, 0}=0\right) & i=1, \ldots, N \text { e } t=1, \ldots, T .
\end{array}
$$

A função objetivo (2.18) a ser minimizada representa a soma dos custos de estoque, produção e preparação dos $N$ itens ao longo dos $T$ períodos. As equações (2.19) representam o balanceamento de estoque de cada item no final de cada período. As inequações (2.20) indicam as limitações de capacidade em cada período e (2.21) são restrições lógicas que indicam a necessidade de preparação quando há produção. As demais definem variáveis binárias e não negatividade.

Este problema denotado por CLSP (the capacited lot sizing problem) é uma extensão do problema de Wagner e Whitin (1958) com restrições de capacidade e vários itens. Este modelo de programação inteira mista é classificado como large bucket, já que, vários itens podem ser produzidos no mesmo período. Resolver o problema CLSP na otimalidade 
com tempo de preparação nulo é NP-difícil e se considerado tempo de preparação positivo é NP-completo. Analogamente ao modelo (2.6)-(2.10), pode-se considerar estoques negativos.

Encontra-se na literatura métodos ótimos, quase-ótimos e heurísticos para resolver o problema. Trigeiro et al. (1989) desenvolveram um método heurístico que consiste em relaxar as restrições de capacidade (2.20) aplicando a técnica de relaxação Lagrangiana. Assim, são obtidos $N$ subproblemas sem restrições de capacidade que foram resolvidos utilizando um algoritmo de programação dinâmica. Em seguida, se a solução for factível, aplica-se um método de factibilização que transfere produção entre períodos, na tentativa de factibilizar a solução e, finalmente, atualiza os multiplicadores duais utilizando o método do subgradiente.

Araújo e Arenales (2000) modificaram o método de Trigeiro et al., considerando as condições de folgas complementares como um alvo no método de factibilização e encontraram resultados melhores para exemplos gerados aleatoriamente.

Dentre os que desenvolveram métodos ótimos e quase ótimos destaca-se: Diaby et al. (1992), que desenvolveram um método do tipo branch-and-bound no qual, os limitantes foram gerados por relaxação Lagrangiana e os custos duais atualizados pelo método do subgradiente. Toledo (1994) representou o problema como uma rede generalizada e desenvolveu um método ótimo. O método é um algoritmo branch-and-bound especializado, no qual em cada nó é resolvido um problema de custo mínimo em uma rede generalizada.

Segundo Araújo (2003), devido à complexidade do problema, os procedimentos ótimos resolvem apenas problemas pequenos em tempo razoável, enquanto que os procedimentos heurísticos conseguem obter boas soluções para problemas de maior porte. Experimentos com pacotes comerciais sofisticados confirmam esta afirmação.

Outros estudos referentes a resolução do problema CLSP são apresentados em Karimi et al. (2003).

\subsubsection{Problemas de dimensionamento de lotes multiestágio}

A característica do problema de dimensionamento de lotes multiestágio é a presença de itens dependentes no planejamento de produção, isto é, a produção de um item depende da produção de um ou mais itens que o precedem, gerando uma demanda interna destes 
itens.

Como forma de exemplificar esta situação, considere a Figura 2.1. Define-se $r_{i, j}$ a quantidade do item $i$ necessária para produzir uma unidade do item $j$. Desta forma, uma demanda interna no período $t$ surge, por exemplo, para o item 4 na quantidade $r_{4,1} X_{1, t}+r_{4,2} X_{2, t}$ (representado na Figura 2.1).

Esta relação pode ser formulada como $\sum_{j \in S u c(i)} r_{i, j} X_{j, t}$, considerando $S u c(i)$ o conjunto de itens dependentes de $i$.

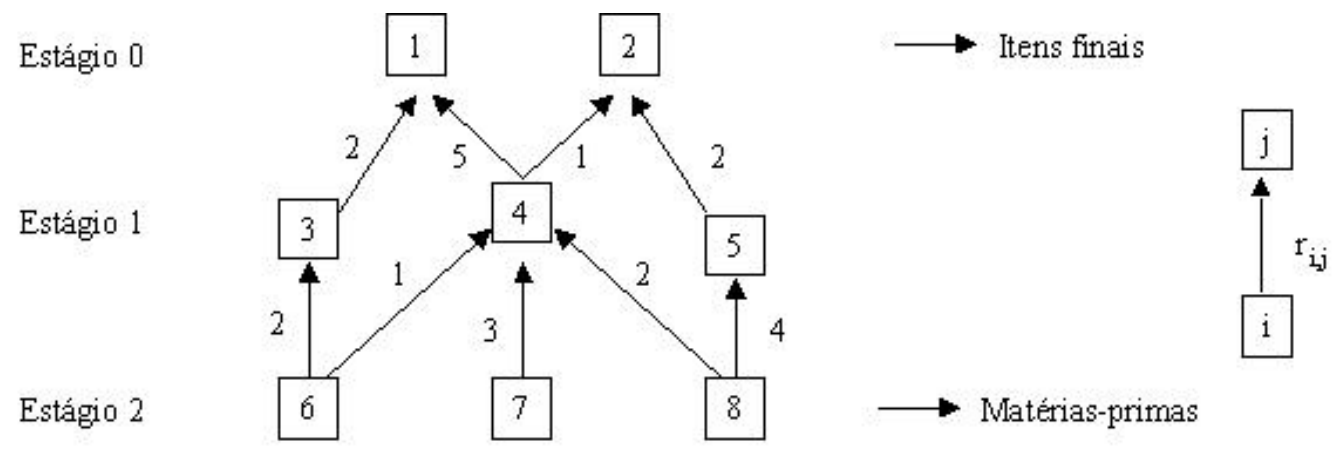

Figura 2.1: Exemplo de estrutura geral de produto.

Para obter um modelo para o problema multiestágio são adicionados alguns dados ao modelo de dimensionamento de lotes monoestágio (2.18)-(2.23):

$r_{i, j}: \quad$ unidades do item $i$ necessárias para compor uma unidade do item $j$;

$S u c(i)$ : conjunto dos itens sucessores imediatos do item $i$.

Formulação do problema:

Minimizar

$$
\sum_{t}^{T} \sum_{i}^{N}\left(H_{i, t} I_{i, t}+c_{i, t} X_{i, t}+S_{i, t} Y_{i, t}\right)
$$

Sujeito a:

$$
\begin{array}{cl}
I_{i, t-1}+X_{i, t}-I_{i, t}=d_{i, t}+\sum_{j \in \operatorname{Suc}(i)} r_{i, j} X_{j, t} & i=1, \ldots, N \text { e } t=1, \ldots, T \\
\sum_{i}^{N} b_{i} X_{i, t}+\sum_{i}^{N} s_{i} Y_{i, t} \leq \operatorname{cap}_{t} & t=1, \ldots, T \\
X_{i, t}-G Y_{i, t} \leq 0 & i=1, \ldots, N \text { e } t=1, \ldots, T \\
Y_{i, t} \in\{0,1\} & i=1, \ldots, N \text { e } t=1, \ldots, T
\end{array}
$$




$$
X_{i, t} \geq 0 \text { e } I_{i, t} \geq 0 \quad\left(I_{i, 0}=0\right) \quad i=1, \ldots, N \text { e } t=1, \ldots, T .
$$

Este novo modelo difere do modelo monoestágio (2.18)-(2.23) apenas pelas restrições de balanceamento de estoque, sendo que (2.25) considera a demanda dependente, que caracteriza o problema de dimensionamento de lotes multiestágio.

Nos problemas monoestágios, uma técnica utilizada para a resolução consiste em relaxar as condições de capacidade e resolver problemas menores para cada item. No caso de problemas multiestágio, devido às restrições (2.25) de balanceamento de estoque, não é possível decompor o modelo por itens. Santos (2000) destaca uma reformulação do problema em termos de estoque de escalão, que consiste numa mudança de variáveis, facilitando a decomposição do problema por item.

Maes et al. (1991) apresentam uma heurística para resolver o problema com restrições de capacidade em mais de um estágio. Ignoram as variáveis inteiras e resolvem o problema linear. Em seguida, testam três heurísticas de arredondamento para encontrar as variáveis binárias. Esta linha será seguida nesta pesquisa.

\subsection{O Setor de fundições}

Os processos de fundição constituem basicamente em fabricar os moldes, preparar e fundir os metais, que são então vazados nos moldes já prontos. Após a solidificação da liga, a peça fundida é retirada e passa pelos acabamentos finais.

As fundições são constituidas basicamente por fornos e máquinas de moldagem e o uso destes dois tipos de equipamentos pode ser determinado pelo planejamento e programação da produção na fundição.

No caso em que se tem várias ligas, a programação da produção numa fundição tem dois momentos importantes e interligados que consistem na programação de cada forno, na qual é definida a liga a ser fundida num determinado período e a programação das máquinas de moldagem, onde são definidos os moldes a serem produzidos.

O setor de fundições pode ser dividido entre as fundições cativas e as fundições de mercado. As cativas são geralmente vinculadas a grandes empresas, com produção em série e em grandes quantidades de cada item, está baseada no consumo próprio da empresa. 
Por outro lado, as fundições de mercado atendem demandas variadas, acarretando a produção bastante diversificada de peças, pesos e composições.

Em sua pesquisa, Fernandes e Leite (2002) observaram o interesse das fundições de mercado em investir em sistemas automatizados para gestão da produção. As decisões baseadas no bom senso e na experiência do administrador do processo não tem sido suficientes no planejamento da produção, ocasionando muitas vezes, problemas como o atraso no fornecimento dos pedidos, falta de matéria prima e mal uso de equipamentos.

Santos-Meza et al. (2001) estudaram um problema prático numa fundição de médio porte com apenas um forno em operação por período, constituindo o gargalo do processo produtivo, e várias máquinas de moldagem que produzem diferentes tipos de itens com demandas conhecidas, que devem ser feitos com diferentes tipos de ligas. O modelo proposto é de dimensionamento de lotes monoestágio com restrições de capacidade, máquinas paralelas e múltiplos itens. O modelo de programação inteira mista é resolvido por um método heurístico baseado numa relaxação particular do problema.

Em Araújo e Arenales (2003) foram realizadas extensões do modelo e do método de solução proposto por Santos-Meza et al. (2001), considerando custos de preparação e admitindo atrasos na data de entrega.

Outro trabalho orientado para fundições de pequeno porte foi desenvolvido por Silva (2001). Foi desenvolvido um método heurístico de solução baseado numa heurística gulosa de aspiração, em que vários problemas da mochila são resolvidos, sendo a capacidade do forno igual à capacidade da mochila.

Um caso prático de fundição de pequeno porte foi estudado por Araújo (2003). A situação foi modelada como um problema de otimização discreta, com restrição de capacidade, custo de preparação e a possibilidade de atraso no atendimento da demanda. O objetivo principal é minimizar os atrasos. O método de solução consiste num método de horizonte rolante, no qual, o autor utilizou busca local para fixar algumas variáveis a cada etapa do método.

Tonaki (2006) decompôs o modelo apresentado por Araújo (2003) e desenvolveu uma heurística lagrangiana baseada em transferências. Este procedimento será melhor estudado no capítulo 3 deste trabalho.

A seguir, são apresentadas algumas restrições típicas encontradas na prática (Araújo, 
2003).

O principal equipamento de uma fundição é o forno (ou conjunto de fornos) que, na maioria dos casos, é o gargalo do processo produtivo. Portanto, em geral, é necessário respeitar a capacidade de cada forno, que pode ser representada por restrições do tipo:

$$
\sum_{i} \rho_{i} X_{i, t} \leq \operatorname{cap}_{t}^{F} \quad t=1, \ldots, T
$$

em que:

$\rho_{i}: \quad$ peso unitário bruto do item $i$

$X_{i, t}$ : quantidade produzida do item $i$ no período $t$;

$\operatorname{cap}_{t}^{F}$ : capacidade do forno $F$ no período $t$.

Estas restrições estabelecem que a cada período, a soma do peso dos itens produzidos não pode ultrapassar o peso que o forno suporta. Quando está disponível mais de um forno, cada qual com sua capacidade, serão necessárias tantas restrições do tipo (2.30) quantos forem os fornos, com ligeira redefinição das variáveis de decisão.

Pode ocorrer também, que alguns fornos não possam estar ligados simultaneamente devido ao sistema elétrico no qual estão inseridos.

Da mesma maneira que foi considerada a limitação para cada forno, quando este representava o gargalo da produção, assim ocorre nas máquinas de moldagem (geralmente em fundições maiores), tornando-se necessário considerar a capacidade de moldagem destas máquinas:

$$
\sum_{i} \frac{1}{a_{i}} X_{i, t} \leq \operatorname{cap}_{t}^{M} \quad t=1, \ldots, T,
$$

em que:

$a_{i}$ : $\quad$ quantidade do item $i$ que a máquina consegue moldar por hora;

$\operatorname{cap}_{t}^{M}$ : quantidade de horas disponíveis da máquina $M$ no período $t$.

Quando existe mais de uma máquina de moldagem, serão necessárias tantas restrições quanto forem o número de máquinas, com ligeira redefinição nas variáveis de decisão. 
Pode existir uma restrição particular em que apenas uma certa máquina pode ser usada para moldar um determinado item.

Quando um item pode ser produzido apenas por um tipo específico de liga, considerase uma alteração na restrição (2.30)

$$
\sum_{i \in S(k)} \rho_{i} X_{i, t} \leq \operatorname{cap}_{t}^{F} Y_{k, t} \quad t=1, \ldots, T
$$

em que:

$Y_{k, t}= \begin{cases}1, & \text { se o forno é carregado com a liga } k \text { no período } t \\ 0, & \text { caso contrário }\end{cases}$

$S(k)$ : conjunto de itens que são produzidos a partir da liga $k$.

Ou seja, se é produzida a liga $k$, então é possível produzir os itens que dependem desta liga.

Outras características que aparecem em algumas fundições são a presença do tempo e/ou custo de preparação e a dependência ou não destes em relação a seqüencia de fabricação. A presença destes fatores pode ocorrer tanto na troca de ligas no forno, como na troca de itens pela máquina de moldagem e variáveis binárias são usadas no modelo.

Os objetivos da modelagem do problema podem enfocar diferentes pontos. Desta maneira, a função objetivo do problema pode visar por exemplo, minimizar os custos, minimizar os atrasos, ou maximizar a utilização dos fornos, entre outros.

O modelo estudado especificamente para o setor de fundições também pode ser utilizado em outros setores industriais que organizam seu processo produtivo em duas etapas dependentes: preparação da matéria prima e aplicação desta nos produtos finais. Dentre estes setores, é possível citar as empresas de bebidas, que num primeiro momento preparam o xarope (matéria prima para a bebida) e depois o utilizam no setor de engarrafamento para a fabricação das bebidas em diferentes tipos de embalagens.

Araújo (2003) comenta que em muitos casos, resolver problemas de planejamento e programação da produção em fundições maiores pode ser mais simples do que em fundições pequenas, em que os dados são mais imprecisos e a variedade de ligas e itens é maior. 


\subsubsection{Uma fundição de pequeno porte}

Araújo (2003) apresenta um estudo para uma fundição de pequeno porte, com moldagem manual, forno por indução magnética e a mistura é despejada no molde com vazamento por gravidade. Os itens apresentam forma, tamanho e demanda bastante variadas. O problema foi escrito como um modelo de otimização discreta para planejamento e programação da produção, e resolvido por métodos que combinam a estratégia de horizonte rolante, relaxe-e-fixe e busca local.

A fundição trabalha conforme o processo de produção esquematizado na Figura 2.2 .

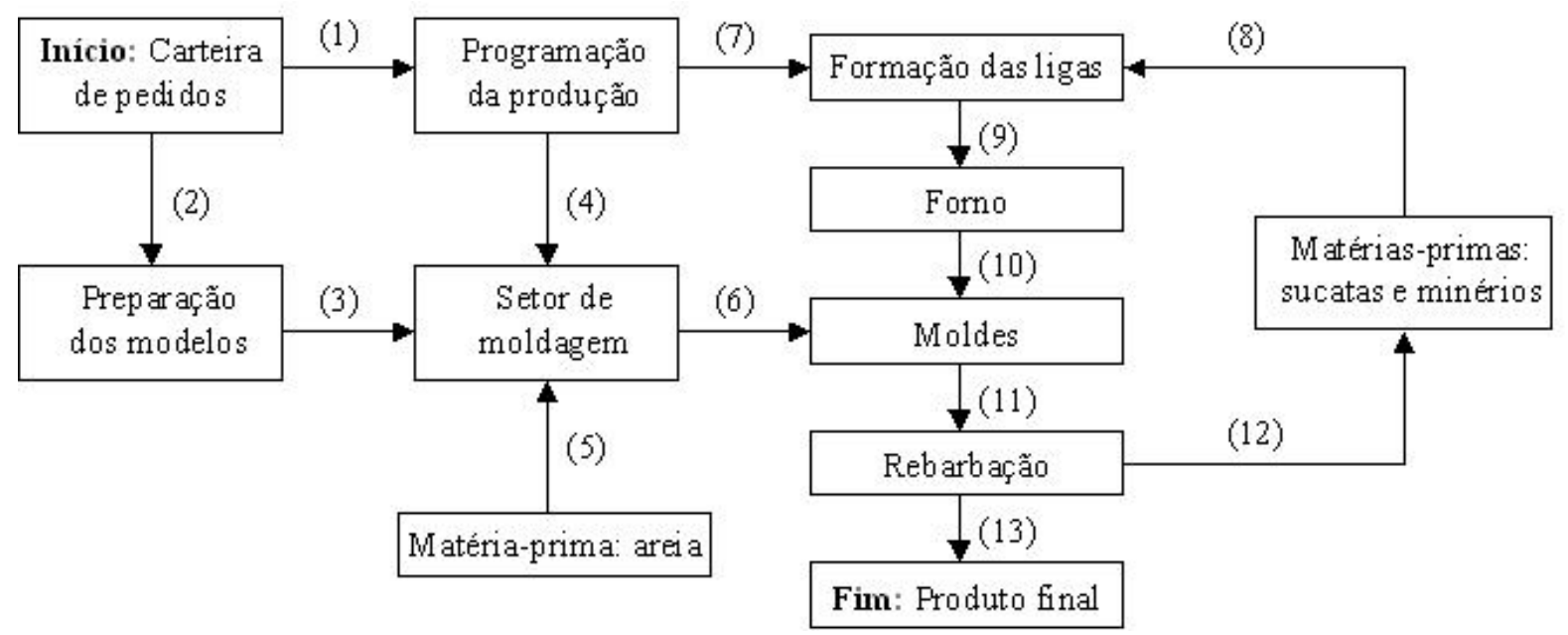

Figura 2.2: Processo produtivo da fundição. Fonte Araújo(2003).

$\mathrm{Na}$ carteira de pedidos consta a demanda de cada item e os prazos de entrega. Estas informações são repassadas para o setor onde é feita a programação da produção(1) e também para o setor responsável pela preparação dos modelos(2). Em geral, os modelos são fornecidos pelos clientes e são utilizados para fazer os moldes dos itens.

As decisões tomadas pela programação da produção são passadas para o setor de moldagem(4), que utiliza a areia como matéria prima(5) para a fabricação dos moldes(6).

No setor de programação da produção também são tomadas decisões quanto à formação das ligas(7), que são formadas da mistura de sucatas e minérios de ferro(8).

Esta mistura é levada ao forno(9) para ser fundida e então vazada nos moldes(10) já preparados. O tempo de solidificação na maioria das ligas é de dez minutos. Neste 
estágio a liga é submetida a um choque térmico, ou seja, é mergulhada na água.

O próximo passo é a rebarbação(11) na qual são retirados os canais de vazamento e massalotes, que voltam a ser matéria-prima(12). Após a rebarbação, a peça já é considerada produto final(13).

O modelo de otimização discreta proposto para este caso (Araújo, 2003), tem como objetivo diminuir os atrasos na entrega da demanda e diminuir os custos com estocagem e preparação. Para isso, os seguintes dados são utilizados:

Índices:

$t=1, \ldots, T:$ períodos de tempo (cargas do forno);

$i=1, \ldots, N$ : tipos de itens;

$k=1, \ldots, K:$ tipos de ligas.

Dados do problema:

cap : capacidade do forno por período $t$;

$L$ : $\quad$ número máximo de cargas do forno por dia;

$\rho_{i}: \quad$ peso bruto do item $i$;

$d_{i, t}: \quad$ demanda do item $i$ no período $t$

$S(k)$ : conjunto de itens $i$ que usam a liga $k$ (cada item utiliza um, e somente um, tipo de liga, ou seja: $\{1, \ldots, N\}=S(1) \cup \ldots \cup S(K), S(h) \cap S(j)=\emptyset, \forall h \neq j)$;

$H_{i, t}^{-}$: $\quad$ penalidade pelo atraso na entrega de uma unidade do item $i$ no final do período $t$;

$H_{i, t}^{+}$: $\quad$ penalidade por antecipação de uma unidade do item $i$ no final do período $t$;

$s_{k}: \quad$ penalidade por preparação da liga $k$.

Variáveis do problema:

$X_{i, t}$ : quantidade do item $i$ produzida no período $t$;

$I_{i, t}^{+}: \quad$ quantidade estocada do item $i$ no final do período $t$;

$I_{i, t}^{-}: \quad$ quantidade atrasada do item $i$ no final do período $t$;

$Y_{k, t}$ : variável binária $\left(Y_{k, t}=1\right.$ indica que o forno é preparado para produzir a liga $k$ no período $t$, caso contrário, $\left.Y_{k, t}=0\right)$; 
$Z_{k, t}$ : $\quad$ variável que indica se o custo de preparação para a liga $k$ incide no período $t: Z_{k, t}=0$ se $Y_{k, t-1} \geq Y_{k, t}$ e $Z_{k, t}=1$ se $Y_{k, t-1}<Y_{k, t}$. (Embora esta variável seja binária em essência, pode ser modelada como contínua).

Formulação do problema:

Minimizar

$$
\sum_{i=1}^{N} \sum_{t=1}^{T}\left(H_{i, t}^{-} I_{i, t}^{-}+H_{i, t}^{+} I_{i, t}^{+}\right)+\sum_{k=1}^{K} \sum_{t=1}^{T}\left(s_{k} Z_{k, t}\right)
$$

Sujeito a:

$$
\begin{array}{cl}
I_{i, t-1}^{+}-I_{i, t-1}^{-}+X_{i, t}-I_{i, t}^{+}+I_{i, t}^{-}=d_{i, t} & i=1, \ldots, N \text { e } t=1, \ldots, T \\
\sum_{i \in S(k)} \rho_{i} X_{i, t} \leq c a p Y_{k, t} & k=1, \ldots, K \text { e } t=1, \ldots, T \\
\sum_{k=1}^{K} Y_{k, t} \leq 1 & t=1, \ldots, T \\
Z_{k, t} \geq Y_{k, t}-Y_{k, t-1} & k=1, \ldots, K \text { e } t=1, \ldots, T \\
Y_{k, t} \in\{0,1\} \quad\left(Y_{k, 0}=0\right) & k=1, \ldots, K \text { e } t=1, \ldots, T \\
Z_{k, t} \geq 0 & k=1, \ldots, K \text { e } t=1, \ldots, T \\
X_{i, t} \geq 0 \text { e inteiro } & i=1, \ldots, N \text { e } t=1, \ldots, T \\
I_{i, t}^{+} \geq 0 \text { e } I_{i, t}^{-} \geq 0 & i=1, \ldots, N \text { e } t=1, \ldots, T .
\end{array}
$$

Neste modelo é permitido que ocorram atrasos na entrega dos itens.

A quantidade de cada item atrasado é definida por $I_{i, t}^{-}$e a quantidade de cada item em estoque é $I_{i, t}^{+}$. Então, é possível analisar a variável de estoque pela relação $I_{i, t}=I_{i, t}^{+}-I_{i, t}^{-}$. Quando existe atraso na entrega $\left(I_{i, t}^{-}>0\right)$, não há estoque $\left(I_{i, t}^{+}=0\right)$, portanto, $I_{i, t}<0$. Quando existe estoque para um certo item $\left(I_{i, t}^{+}>0\right)$, não há atrasos $\left(I_{i, t}^{-}=0\right)$, fazendo com que $I_{i, t}>0$.

Sendo a maior preocupação da empresa a minimização dos atrasos na entrega dos itens, a penalidade considerada em $H_{i, t}^{-}$é maior do que $H_{i, t}^{+}$. A função objetivo penaliza também a ocorrência de preparação, tentando evitar as trocas de ligas entre os períodos.

As restrições (2.34) são de balanceamento de estoque. No conjunto de inequações (2.35) está sendo considerada a capacidade do forno. Além disso, a produção dos itens para cada liga só ocorre se o forno for preparado para ela. As restrições (2.36) garantem que apenas uma liga pode ser produzida em cada carga do forno. As restrições (2.37) 
decidem quando será cobrado ou não o custo de preparação. Nas restrições (2.39), mesmo considerando as variáveis contínuas, é possível observar por (2.37) e (2.38) que serão variáveis binárias. As variáveis de produção foram mantidas inteiras, restrições (2.40).

Araújo (2003) destaca que devido as características da empresa, onde existem pedidos de apenas uma ou duas quantidades de itens pesados, as variáveis de produção $X_{i, t}$ não podem ser relaxadas como na maioria dos modelos de dimensionamento de lotes. Seria possível relaxar tais variáveis para alguns itens leves, que têm quantidades demandadas relativamente grandes. As heurísticas de arredondamento, foco principal desta pesquisa, focalizam as variáveis de produção $X_{i, t}$ cujo arredondamento pode não ser trivial.

Em outro trabalho mais recente, Araújo et al. (2006), os autores apresentam um modelo semelhante ao (2.33)-(2.41), considerando períodos e subperíodos. Este novo modelo será discutido no capítulo 4 .

De maneira geral, as situações encontradas nas empresas de fundição podem ser modeladas por otimização discreta e são, em geral, problemas de otimização combinatória difíceis de serem resolvidos, de classes NP-difícel e NP-completo (Araújo, 2003).

O problema de dimensionamento de lotes monoestágio consiste em determinar o montante de produção em cada período de tempo do horizonte de planejamento finito, considerando a demanda dinâmica e conhecida, com ocorrência de estoque e limitantes de capacidade e com custo de preparação. Quando considerada a produção de um único tipo de item, este problema é NP-difícil (Florian et al., 1980). Maes et al. (1991) mostraram que, para o caso de multi-itens, o problema é NP-completo. Desta forma, os estudos são direcionados para o desenvolvimento de heurísticas.

Os métodos de solução para estes problemas são classificados em três categorias por Karimi et al. (2003), os métodos exatos, as heurísticas de senso comum ou especializadas, e as heurísticas baseadas em otimização matemática.

Nos capítulos seguintes serão apresentadas duas abordagens diferentes para o problema de dimensionamento de lotes para fundições de pequeno porte. Ambos estão baseados no modelo (2.33)-(2.41). 


\section{Capítulo 3}

\section{Uma heurística baseada na decomposição do problema}

Recentemente, Tonaki (2006) apresentou um estudo do planejamento da produção em fundições de pequeno porte, baseado no trabalho de Araújo (2003). Foi desenvolvida uma abordagem baseada na decomposição do problema em dois subproblemas: o planejamento da produção das ligas e o planejamento da produção dos itens. Para a resolução destes dois subproblemas foi desenvolvida uma heurística lagrangiana baseada em tansferências.

No decorrer deste capítulo são apresentados os conceitos para a decomposição do modelo (2.33)-(2.41) em dois subproblemas. Em seguida são apresentadas as estratégias de resolução apresentadas por Tonaki.

\subsection{Modelo matemático completo}

Tonaki (2006) baseou-se no modelo matemático proposto por Araújo (2003), apresentado no capítulo anterior (2.33)-(2.41), no qual as demandas $d_{i, t}$ são positivas somente no último período de cada dia da programação, sendo nula nos demais.

Os custos de estoque e atraso dos itens $H_{i, t}^{+}$e $H_{i, t}^{-}$também são positivos somente no último período de cada dia e nulos nos demais, e são calculados por Tonaki da seguinte maneira:

$$
\begin{aligned}
& \text { Se } \alpha_{i, t} \geq 0 \text { então } H_{i, t}^{-}=\rho_{i}\left(\alpha_{i, t}+1\right) \text { e } H_{i, t}^{+}=G \\
& \text { senão } H_{i, t}^{+}=\frac{\rho_{i}}{10} \text { e } H_{i, t}^{-}=G,
\end{aligned}
$$


sendo $\alpha_{i, t}>0$ a quantidade de dias de atraso do item $i$ no período $t$. Para pedidos que não estão em atraso, $\alpha_{i, t}$ recebe valores negativos, dependendo da quantidade de dias entre o início da programação e do dia da entrega do pedido e $\alpha_{i, t}=0$ significa que o prazo de entrega do item vence no dia em que está sendo feita a programação.

\subsection{Decomposição do modelo completo}

O problema original é decomposto em dois subproblemas: o planejamento da produção das ligas e o planejamento da produção dos itens.

\subsubsection{Planejamento da produção das ligas}

Para a definição do problema das ligas, as restrições (2.34) do modelo completo referentes ao balanceamento do estoque em cada período serão reescritas focando a quantidade de cada liga em estoque ou atraso. Para isso, multiplicando cada termo das restrições (2.34) por $\rho_{i}$ é obtida a demanda de liga necessária para produzir o item $i$ no período $t$, como mostrado a seguir:

$$
\rho_{i} I_{i, t-1}^{+}-\rho_{i} I_{i, t-1}^{-}+\rho_{i} X_{i, t}-\rho_{i} I_{i, t}^{+}+\rho_{i} I_{i, t}^{-}=\rho_{i} d_{i, t} \quad i=1, \ldots, N \text { e } t=1, \ldots, T,
$$

em que:

$\rho_{i} X_{i, t}: \quad$ quantidade (em $\mathrm{kg}$ ) do item $i$ produzida no período $t ;$

$\rho_{i} I_{i, t}^{+}$: quantidade estocada (em kg) do item $i$ no período $t ;$

$\rho_{i} I_{i, t}^{-}: \quad$ quantidade atrasada $(\mathrm{em} \mathrm{kg})$ do item $i$ no período $t$;

$\rho_{i} I_{i, t-1}^{+}: \quad$ quantidade estocada (em $\mathrm{kg}$ ) do item $i$ no período $t-1$;

$\rho_{i} I_{i, t-1}^{-}:$quantidade atrasada $(\mathrm{em} \mathrm{kg})$ do item $i$ no período $t-1$;

$\rho_{i} d_{i, t}: \quad$ demanda $(\mathrm{em} \mathrm{kg})$ do item $i$ no período $t$.

Sendo $S(k)$ o conjunto de itens $i$ produzidos a partir da liga $k$, se agrupadas as demandas (em kg de liga) dos itens pertencentes a este conjunto, então é encontrada a quantidade necessária de cada liga $k$, em cada período $t$. De outra forma, são somadas todas as restrições referentes aos itens pertencentes ao conjunto $S(k)$ para cada período:

$$
\sum_{i \in S(k)} \rho_{i} I_{i, t-1}^{+}-\sum_{i \in S(k)} \rho_{i} I_{i, t-1}^{-}+\sum_{i \in S(k)} \rho_{i} X_{i, t}-\sum_{i \in S(k)} \rho_{i} I_{i, t}^{+}+\sum_{i \in S(k)} \rho_{i} I_{i, t}^{-}=\sum_{i \in S(k)} \rho_{i} d_{i, t},
$$


para $k=1, \ldots, K$ e $t=1, \ldots, T$.

Definindo novas variáveis, sendo:

$E_{k, t-1}^{+}=\sum_{i \in S(k)} \rho_{i} I_{i, t-1}^{+}$: quantidade estocada da liga $k$ (em $\mathrm{kg}$ ) no período $t$-1;

$E_{k, t-1}^{-}=\sum_{i \in S(k)} \rho_{i} I_{i, t-1}^{-}: \quad$ quantidade atrasada da liga $k$ (em $\mathrm{kg}$ ) no período $t-1$;

$E_{k, t}^{+}=\sum_{i \in S(k)} \rho_{i} I_{i, t}^{+}: \quad$ quantidade estocada da liga $k$ (em kg) no período $t$;

$E_{k, t}^{-}=\sum_{i \in S(k)} \rho_{i} I_{i, t}^{-}: \quad$ quantidade atrasada da liga $k$ (em $\mathrm{kg}$ ) no período $t$;

$D_{k, t}=\sum_{i \in S(k)} \rho_{i} d_{i, t}: \quad$ demanda da liga $k$ no período $t$.

É possível reescrever as restrições de balanceamento de estoque na forma:

$$
E_{k, t-1}^{+}-E_{k, t-1}^{-}+\sum_{i \in S(k)} \rho_{i} X_{i, t}-E_{k, t}^{+}+E_{k, t}^{-}=D_{k, t} \quad k=1, \ldots, K \text { e } t=1, \ldots, T .
$$

Uma aproximação para (3.1) é agora considerada. Note que $\sum_{i \in S(k)} \rho_{i} X_{i, t}$ fornece a quantidade de liga $k$ produzida no período $t$, que consiste numa carga do forno. Considerando a programação de um dia, em que $L$ cargas podem ser feitas define-se $A_{k, t l} \mathrm{O}$ número de vezes que a liga $k$ é fundida no dia $t$, e quando escolhida a liga para fusão, é considerado que esta liga ocupa a capacidade máxima do forno. Desta forma:

$$
E_{k, t l-1}^{+}-E_{k, t l-1}^{-}+\operatorname{cap}_{k, t l}-E_{k, t l}^{+}+E_{k, t l}^{-}=D_{k, t l} \quad k=1, \ldots, K \text { e } \quad t l=1, \ldots, T l .
$$

Para que seja respeitado o limite de cargas do forno ao dia, vale a relação:

$$
\sum_{k=1}^{K} A_{k, t l} \leq L \quad t l=1, \ldots, T l .
$$

Além disso, a produção da liga ocorre quando houver preparação para a mesma, ou seja:

$$
A_{k, t l} \leq L Y_{k, t l} \quad k=1, \ldots, K \text { e } \quad t l=1, \ldots, T l
$$

Após estas considerações é possível definir o problema para o planejamento da produção das ligas.

Índices:

$t l=1, \ldots, T l: \quad$ dias de programação;

$k=1, \ldots, K: \quad$ tipos de ligas. 
Dados do problema:

cap: capacidade do forno por carga;

$L$ : $\quad$ número máximo de cargas do forno por dia;

$D_{k, t l}:$ demanda da liga $k$ no dia $t l$;

$H_{k, t l}^{-}$: penalidade pelo atraso na entrega de $1 \mathrm{~kg}$ da liga $k$ no dia $t l$;

$H_{k, t l}^{+}$: $\quad$ penalidade por antecipação de $1 \mathrm{~kg}$ da liga $k$ no dia $t l$;

$s_{k}: \quad$ penalidade pela preparação da liga $k$.

Variáveis do problema:

$A_{k, t l}: \quad$ número de vezes que a liga $k$ é fundida no dia $t l$;

$E_{k, t l}^{+}:$quantidade estocada da liga $k$ (em kg) no dia $t l$;

$E_{k, t l}^{-}:$quantidade atrasada da liga $k(\mathrm{em} \mathrm{kg})$ no dia $t l ;$

$Y_{k, t l}$ : variável binária $\left(Y_{k, t l}=1\right.$ indica que o forno é preparado para produzir a liga $k$ no dia $t$, caso contrário, $\left.Y_{k, t l}=0\right)$.

Formulação do problema de planejamento das ligas (uma aproximação):

Minimizar

$$
\sum_{t l=1}^{T l} \sum_{k=1}^{K}\left(H_{k, t l}^{-} E_{k, t l}^{-}+H_{k, t l}^{+} E_{k, t l}^{+}+s_{k} Y_{k, t l}\right)
$$

Sujeito a:

$$
\begin{array}{cl}
E_{k, t l-1}^{+}-E_{k, t l-1}^{-}+c a p A_{k, t l}-E_{k, t l}^{+}+E_{k, t l}^{-}=D_{k, t l} & k=1, \ldots, K \text { e } t l=1, \ldots, T l \text { (3.6) } \\
\sum_{k=1}^{K} A_{k, t l} \leq L & t l=1, \ldots, T l \\
A_{k, t l} \leq L Y_{k, t l} & k=1, \ldots, K \text { e } t l=1, \ldots, T l(3.8) \\
Y_{k, t l} \in\{0,1\} & k=1, \ldots, K \text { e } t l=1, \ldots, T l(3.9) \\
A_{k, t l} \geq 0 \text { e inteiro } & k=1, \ldots, K \text { e } t l=1, \ldots, T l(3.10) \\
E_{k, t l}^{+} \geq 0 \text { e } E_{k, t l}^{-} \geq 0 & k=1, \ldots, K \text { e } t l=1, \ldots, T l .(3.11)
\end{array}
$$

Considerando $t l=1, \ldots, T l$ e $G$ um número grande, os custos de atraso e estoque foram definidos segundo Tonaki (2006) como:

$$
\begin{aligned}
& \text { Se } \alpha_{k, t l} \geq 0 \text { então } H_{k, t l}^{-}=\alpha_{k, t l}+1 \text { e } H_{k, t l}^{+}=G \\
& \text { senão } H_{k, t l}^{+}=\frac{1}{10} \text { e } H_{k, t l}^{-}=G .
\end{aligned}
$$


Para encontrar o valor $\alpha_{k, t l}$, a autora admite um novo número de ligas Kaux $($ Kaux $\geq K)$, e considera uma liga diferente um agrupamento de itens até ser atingido pelo menos $360 \mathrm{~kg}$, e o número de dias de atraso no início da programação é a média ponderada do número de dias em atraso no início da programação dos itens pertencentes à liga $k$, e a quantidade (em kg) demandada dos itens, ou seja:

$$
\frac{\sum_{i \in S(k)} \alpha_{i, 1} \text { pesodemandado }_{i}}{\sum_{i \in S(k)} \text { pesodemandado }_{i}},
$$

em que:

$$
\operatorname{pesodemandado}_{i}=\sum_{t=1}^{T} d_{i, t} \rho_{i} \text {. }
$$

\subsubsection{Planejamento da produção dos itens}

A resolução do modelo de planejamento da produção das ligas fornece o valor da variáveis $A_{k, t l}$, para $k=1, \ldots, K$ e $t l=1, \ldots, T l$, que indicam quantas fornadas são utilizadas por cada liga durante cada dia $t l$ do horizonte de planejamento. A partir destes dados são definidos os períodos de preparação $W_{k, t}, k=1, \ldots, K$ e $t=1, \ldots, T$, ou seja, se o forno é ou não preparado para a liga $k$, na carga $t$.

Para cada liga $k$ é resolvido um problema de dimensionamento de lotes, determinando a produção dos itens. O problema da produção dos itens é definido da seguinte maneira:

Índices:

$i \in S(k): \quad$ tipos de itens da liga $k$;

$t=1, \ldots, T:$ períodos de tempo (cargas do forno).

Dados do problema:

cap : capacidade do forno por período;

$\rho_{i}: \quad$ peso bruto do item $i$;

$d_{i, t}$ : demanda do item $i$ no período $t$;

$S(k)$ : conjunto de itens $i$ que usam a liga $k$ (cada item utiliza um, e somente um, tipo de liga, ou seja: $\{1, \ldots, N\}=S(1) \cup \ldots \cup S(k), S(h) \cap S(j)=\emptyset, \forall h \neq j)$;

$H_{i, t}^{-}$: $\quad$ penalidade pelo atraso na entrega de uma unidade do item $i$ no período $t$; 
$H_{i, t}^{+}$: $\quad$ penalidade por antecipação de uma unidade do item $i$ no período $t$;

$W_{k, t}$ : valor binário determinado a partir da solução do modelo das ligas $\left(W_{k, t}=1\right.$ indica que o forno é preparado para produzir a liga $k$ no período $t$, caso contrário, $\left.W_{k, t}=0\right)$.

Variáveis do problema:

$X_{i, t}:$ quantidade do item $i$ produzida no período $t$;

$I_{i, t}^{+}$: quantidade estocada do item $i$ no período $t$;

$I_{i, t}^{-}: \quad$ quantidade atrasada do item $i$ no período $t$.

Formulação do problema: $\left(P_{k}, k=1, \ldots, K\right)$

Minimizar

$$
\sum_{t=1}^{T} \sum_{i \in S(k)}\left(H_{i, t}^{-} I_{i, t}^{-}+H_{i, t}^{+} I_{i, t}^{+}\right)
$$

Sujeito a:

$$
\begin{array}{cl}
I_{i, t-1}^{+}-I_{i, t-1}^{-}+X_{i, t}-I_{i, t}^{+}+I_{i, t}^{-}=d_{i, t} & i \in S(k) \text { e } t=1, \ldots, T \\
\sum_{i \in S(k)} \rho_{i} X_{i, t} \leq \operatorname{cap} W_{k, t} & t=1, \ldots, T \\
X_{i, t} \geq 0 \text { e inteiro } & i \in S(k) \text { e } t=1, \ldots, T \\
I_{i, t}^{+} \geq 0 \text { e } I_{i, t}^{-} \geq 0 & i \in S(k) \text { e } t=1, \ldots, T .
\end{array}
$$

As restrições (3.13) indicam o balanceamento de estoque para os itens produzidos a partir da liga $k$ em cada período $t$, mas estes itens são produzidos se houve a preparação do forno para esta liga $k$, condição representada por (3.14).

\subsection{Heurística para o problema decomposto}

A heurística apresentada por Tonaki (2006) foi baseada numa heurística lagrangiana e é composta por três fases: obtenção da solução inicial, factibilização e melhoria.

\subsubsection{Heurística lagrangiana para o modelo das ligas}

Considere o modelo (3.5)-(3.11) do planejamento das ligas, ao que é aplicada relaxação lagrangiana nas restrições (3.7) de capacidade, considerando $\mu_{t l}, t l=1, \ldots, T l$, os multi- 
plicadores lagrangianos associados. O problema lagrangiano é dado por:

$$
\begin{aligned}
& g\left(\mu_{t l}\right)=\text { Minimizar } \\
& \sum_{t l=1}^{T l} \sum_{\text {kaux }=1}^{\text {Kaux }}\left(H_{\text {kaux }, t l}^{-} E_{\text {kaux }, t l}^{-}+H_{\text {kaux }, t l}^{+} E_{\text {kaux }, t l}^{+}+s_{\text {kaux }} Y_{\text {kaux }, t l}\right)+\sum_{t l=1}^{T l} \mu_{t l}\left(\sum_{k a u x=1}^{\text {Kaux }} A_{k a u x, t l}-L\right)
\end{aligned}
$$

Sujeito a:

$$
\begin{array}{cl}
E_{k, t l-1}^{+}-E_{k, t l-1}^{-}+\operatorname{cap}_{k, t l}-E_{k, t l}^{+}+E_{k, t l}^{-}=D_{k, t l} & k=1, \ldots, K \text { e } t l=1, \ldots, T l \\
A_{k, t l} \leq L Y_{k, t l} & k=1, \ldots, K \text { e } t l=1, \ldots, T l \\
Y_{k, t l} \in\{0,1\} & k=1, \ldots, K \text { e } t l=1, \ldots, T l \\
A_{k, t l} \geq 0 \text { e inteiro } & k=1, \ldots, K \text { e } t l=1, \ldots, T l \\
E_{k, t l}^{+} \geq 0 \text { e } E_{k, t l}^{-} \geq 0 & k=1, \ldots, K \text { e } t l=1, \ldots, T l .
\end{array}
$$

O problema lagrangiano pode ser decomposto como a soma de Kaux subproblemas independentes. Estes subproblemas podem ser resolvidos na otimalidade pelo algoritmo de programação dinâmica proposto por Zangwill (1969).

A função dual de $g\left(\mu_{t l}\right)$ foi maximizada usando o método do subgradiente. Os valores dos parâmetros e número de iterações utilizados pelo método foram previamente estabelecidos por Tonaki (2006).

Suponha que seja encontrada uma solução inicial infactível para o problema não relaxado. A heurística consiste em obter uma solução factível por um processo de factibilização e, em seguida, buscar soluções que correspondam a custos menores para a função objetivo por um processo de melhoria. A heurística é resumida no algoritmo seguinte.

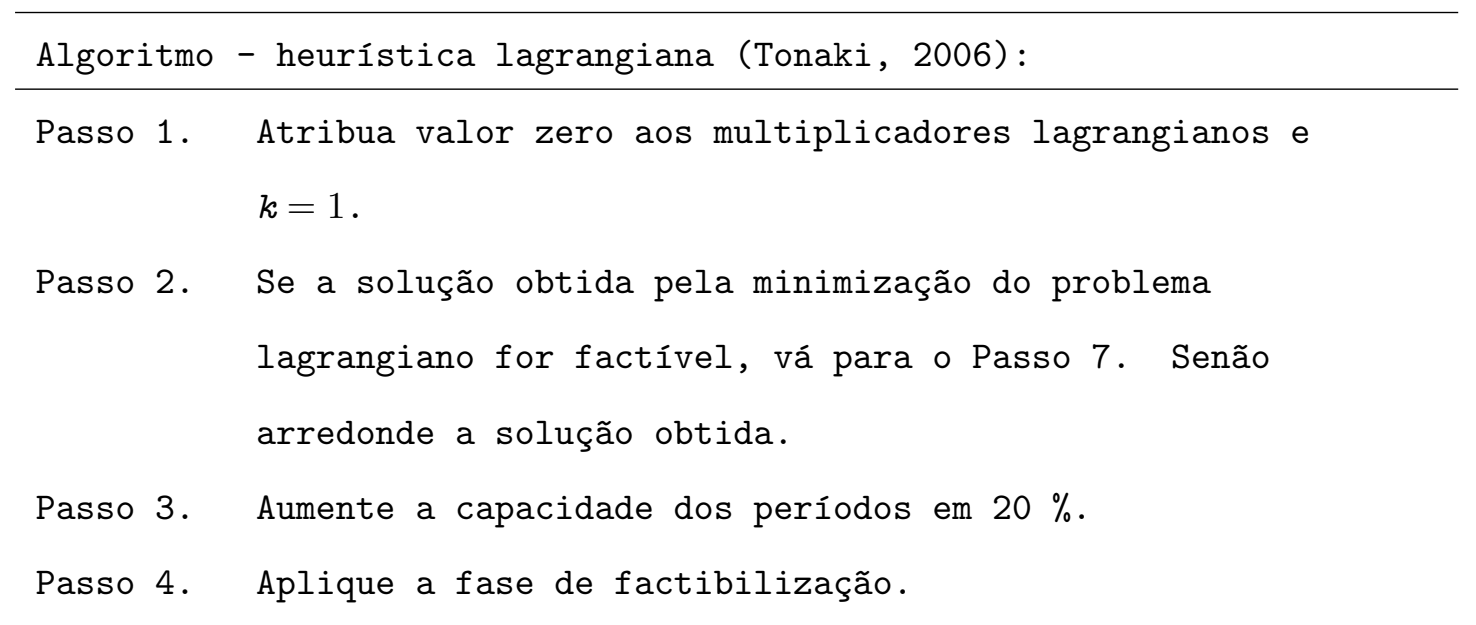


Passo 5. Retorne à capacidade original, se a solução for factível vá para o Passo 7. Aplique a fase de factibilização.

Passo 6. Se a solução for factível aplique a fase de melhoria e vá para o Passo 7, caso contrário vá para o Passo 8.

Passo 7. Atualize a melhor solução.

Passo 8. Se a solução atual é ótima ou $k=\max _{-} i t$ então PARE, senão execute mais uma iteração do método do subgradiente $(k=k+1)$ e volte ao Passo 2 .

\section{Fase de factiblização}

A fase de factibilização é aplicada para o problema lagrangiano a cada passo $k$ do método do subgradiente.

Considere que a solução inicial seja infactível, portanto, há ao menos um dia de programação em que são preenchidas mais fornadas que o permitido. A produção referente a estas fornadas extras é transferida entre os outros períodos.

A fase de factibilização consiste em dois passos, o regressivo e o progressivo.

No passo regressivo, os períodos são analisados conforme a sequência $t l=T l, T l-$ $1, \ldots, 2$. Quando há excesso de produção num período $t l$ ocorre a transferência de produção de $t l$ para um período $t d$, de forma que $1 \leq t d<t l$. Se após todas as transferências do passo regressivo não houver excesso de produção em $t l=1$, foi encontrada uma solução factível e é aplicada a fase de melhoria. Caso contrário, aplica-se o passo progressivo.

No passo progressivo, os períodos são analisados conforme a sequência $t l=1,2, \ldots, T l-$ 1 e quando há excesso de produção em $t$, a transferência ocorre de $t l$ para $t d$ com $t l<t d \leq T l$. Após todas as transferências do passo progressivo é encontrada uma solução factível pois um período fictício $T l$ tem capacidade infinita) e aplica-se a fase de melhoria.

\section{Fase de melhoria}

Considere a solução obtida na fase de factibilização. A fase de melhoria consiste em fazer transferências de produção para períodos em que haja folga de capacidade.

Esta fase é composta de um passo regressivo e outro progressivo. No passo regres- 
sivo, um período com capacidade folgada $t d$ é identificado examinando $t d=T l-1, \ldots, 1$ e são realizadas transferências de produção de $t l=T l, \ldots, t d+1$ para $t d$. Se depois da transferência ainda hover folga em $t d$, o processo é repetido na tentativa de reduzir o custo. O passo progressivo é similar.

\subsubsection{Heurística lagrangiana para o modelo dos itens}

Considere o modelo (3.12)-(3.16) do planejamento dos itens, ao que é aplicada a relaxação lagrangiana nas restrições (3.14) de capacidade, considerando $\mu_{t} \geq 0, t=1, \ldots, T$ os multiplicadores de lagrange associados. É obtido o seguinte problema lagrangiano:

$$
\begin{aligned}
g\left(\mu_{t}\right)= & \text { Minimizar } \\
& \sum_{t=1}^{T} \sum_{i \in S(k)}\left(H_{i, t}^{-} I_{i, t}^{-}+H_{i, t}^{+} I_{i, t}^{+}\right)+\sum_{t=1}^{T} \mu_{t}\left(\sum_{i \in S(k)} \rho_{i} X_{i, t}-\operatorname{cap} W_{k, t}\right)
\end{aligned}
$$

Sujeito a:

$$
\begin{array}{cl}
I_{i, t-1}^{+}-I_{i, t-1}^{-}+X_{i, t}-I_{i, t}^{+}+I_{i, t}^{-}=d_{i, t} & i \in S(k) \text { e } t=1, \ldots, T \\
X_{i, t} \geq 0 \text { e inteiro } & i \in S(k) \text { e } t=1, \ldots, T \\
I_{i, t}^{+} \geq 0 \text { e } I_{i, t}^{-} \geq 0 & i \in S(k) \text { e } t=1, \ldots, T .
\end{array}
$$

A solução obtida do modelo das ligas, apresentado na sessão 3.3.1, indica qual liga é preparada em cada período $t$ (fornada), sendo permitida a produção dos itens $i \in S(k)$ apenas nos períodos em que esta liga $k$ é preparada.

Obedecendo essa condição, o modelo relaxado pode ser decomposto $|S(k)|$ problemas independentes, um para cada item. São resolvidos de forma similar aos subproblemas referentes a $g\left(\mu_{t l}\right)$ e são considerados novos valores para os parâmetros do método do subgradiente.

A heurística proposta para este problema dos itens é baseada na anterior, em que, se a solução inicial é infactível, aplica-se a fase de factibilização e em seguida a fase de melhoria. As tranferências da produção dos itens só pode ocorrer entre períodos em que a liga é preparada.

\section{Fase de factibilização}


Considere que a solução inicial seja infactível, portanto, existe pelo menos uma fornada em que o limite de capacidade é excedido. A fase de factibilização consiste em transferir a produção excedente para outras fornadas, buscando uma solução factível para o modelo dos itens. Esta fase é composta de um passo regressivo e outro progressivo, análogos aos descritos anteriormente.

Após as transferências do passo progressivo é obtida uma solução factível, pois o último período (período fantasma) tem capacidade infinita. Aplica-se em seguida a fase de melhoria.

\section{Fase de melhoria}

Da mesma maneira como no problema das ligas, esta fase analisa a folga de capacidade nas fornadas e realiza transferências de produção, buscando diminuir o custo na função objetivo. Consiste também de um passo regressivo e outro progressivo. 


\section{Capítulo 4}

\section{Modelo de horizonte rolante e}

\section{estratégias de solução}

Araújo (2003) propõe inicialmente a aplicação de uma estratégia de horizonte rolante (Clark et al., 2000) no modelo de dimensionamento de lotes monoestágio (2.33)-(2.41) para fundições de pequeno porte e então resolve o modelo resultante utilizando o método relaxe-e-fixe e um algoritmo de busca local.

Em Araújo et al. (2006), foi apresentada uma nova formulação inteira mista para este problema de fundições de mercado. Neste modelo são considerados $t$ períodos de tempo sobre o horizonte de planejamento finito. Cada um destes períodos, por sua vez, é dividido em períodos menores definidos como subperíodos. A Figura 4.1 representa os períodos e subperíodos sobre o horizonte de planejamento, em que $F_{t}$ indica o primeiro subperíodo do período $t$ e $L_{t}$ o último subperíodo do período $t, \operatorname{com} F_{1}=1$ e $F_{t+1}=L_{t}+1$.

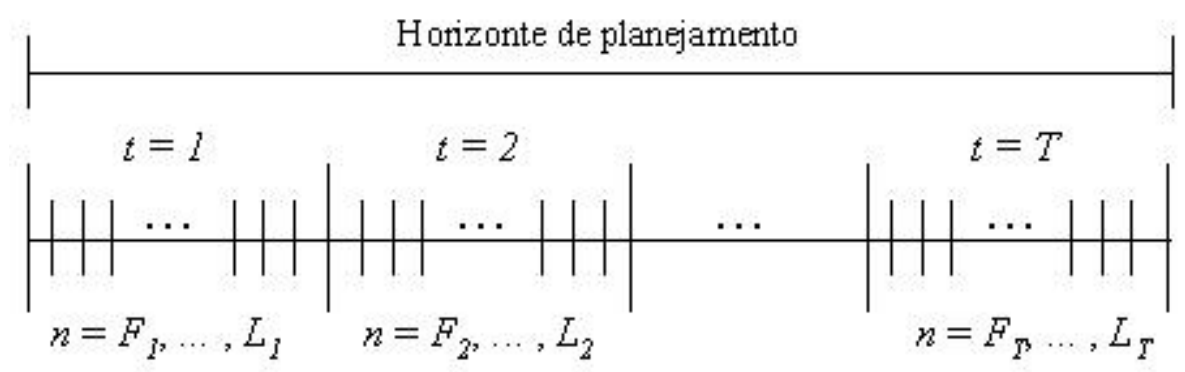

Figura 4.1: Horizonte de planejamento dividido em períodos e subperíodos.

Desta maneira, o horizonte de planejamento está dividido em $L_{T}$ subperíodos ou 
$T$ períodos.

O problema consiste em calcular a quantidade de itens que deve ser produzida em cada um dos $L_{T}$ subperíodos, de forma a minimizar principalmente o atraso na entrega dos itens e, também, os custos de estoque dos itens e preparação do forno. Para isso, Araújo et al. (2006) apresentam a formulação seguinte, considerando ainda o tempo de preparação.

Índices:

$k=1, \ldots, K: \quad$ tipos de ligas;

$i=1, \ldots, N: \quad$ tipos de itens;

$t=1, \ldots, T: \quad$ períodos de tempo (dias, por exemplo);

$n=1, \ldots, L_{T}$ : subperíodos de tempo (fornadas, por exemplo).

Dados do problema:

cap : capacidade $(\mathrm{kg})$ do forno por subperíodo;

$L$ : $\quad$ número máximo de cargas do forno por período;

$\rho_{i}: \quad$ peso bruto do item $i$;

$d_{i, t}: \quad$ demanda do item $i$ no período $t$;

$S(k)$ : conjunto de itens $i$ que usam a liga $k$ (cada item utiliza um, e somente um, tipo de liga, ou seja: $\{1, \ldots, N\}=S(1) \cup \ldots \cup S(K), S(h) \cap S(j)=\emptyset, \forall h \neq j)$;

$H_{i, t}^{-}$: $\quad$ penalidade pelo atraso na entrega do item $i$ no período $t$;

$H_{i, t}^{+}$: $\quad$ penalidade por antecipação do item $i$ no período $t$;

$s_{k}: \quad$ penalidade por preparação da liga $k$;

$s t_{k}: \quad$ tempo de preparação do forno para a liga $k$.

Variáveis do problema:

$X_{i, n}$ : quantidade do item $i$ produzida no subperíodo $n$;

$I_{i, t}^{+}: \quad$ quantidade estocada do item $i$ no período $t$;

$I_{i, t}^{-}: \quad$ quantidade atrasada do item $i$ no período $t$;

$Y_{k, n}$ : variável binária, $Y_{k, n}=1$ indica que o forno é preparado para produzir a liga $k$ no subperíodo $n$, caso contrário, $Y_{k, n}=0$; 
$Z_{k, n}$ : variável que indica se o custo de preparação para a liga $k$ incide no subperíodo $n: Z_{k, n}=0$ se $Y_{k, n-1} \geq Y_{k, n}$ e $Z_{k, n}=1$ se $Y_{k, n-1}<Y_{k, n}$.

Além disso:

$\eta_{t}: \quad$ número de subperíodos no período $t ;$

$F_{t}=1+\sum_{j=1}^{t-1} \eta_{j}: \quad$ primeiro subperíodo do período $t ;$

$L_{t}=F_{t}+\eta_{t}-1: \quad$ último subperíodo do período $t$

$\eta=\sum_{t=1}^{T} \eta_{t}: \quad$ número total de subperíodos no horizonte de planejamento.

Formulação do problema:

Minimizar

$$
\sum_{i=1}^{N} \sum_{t=1}^{T}\left(H_{i, t}^{-} I_{i, t}^{-}+H_{i, t}^{+} I_{i, t}^{+}\right)+\sum_{k=1}^{K} \sum_{n=F_{1}}^{L_{T}}\left(s_{k} Z_{k, n}\right)
$$

Sujeito a:

$$
\begin{array}{cl}
I_{i, t-1}^{+}-I_{i, t-1}^{-}+\sum_{n=F_{t}}^{L_{t}} X_{i, n}-I_{i, t}^{+}+I_{i, t}^{-}=d_{i, t} & i=1, \ldots, N \text { e } t=1, \ldots, T \\
\sum_{i \in S(k)} \rho_{i} X_{i, n}+s t_{k} Z_{k, n} \leq c a p Y_{k, n} & k=1, \ldots, K \text { e } n=F_{1}, \ldots, L_{T} \\
\sum_{k=1}^{K} Y_{k, n}=1 & n=F_{1}, \ldots, L_{T} \\
Z_{k, n} \geq Y_{k, n}-Y_{k, n-1} & k=1, \ldots, K \text { e } n=F_{1}, \ldots, L_{T} \\
Y_{k, n} \in\{0,1\} \quad\left(Y_{k, 0}=0\right) & k=1, \ldots, K \text { e } n=F_{1}, \ldots, L_{T} \\
0 \leq Z_{k, n} \leq 1 & k=1, \ldots, K \text { e } n=F_{1}, \ldots, L_{T} \\
X_{i, n} \geq 0 \text { e inteiro } & i=1, \ldots, N \text { e } n=F_{1}, \ldots, L_{T} \\
I_{i, t}^{+} \geq 0 \text { e } I_{i, t}^{-} \geq 0 & i=1, \ldots, N \text { e } t=1, \ldots, T .
\end{array}
$$

As restrições (4.2) representam o balanceamento de estoque para cada período (dia, por exemplo) e não mais para cada fornada, como proposto no modelo (2.33)-(2.41). A nova formulação gera um número menor de restrições desse tipo.

As restrições (4.3) garantem que só haverá produção dos itens pertencentes à $S(k)$ se a liga $k$ for fundida neste mesmo período. Além disso, a produção é limitada pela capacidade do forno, lembrando que pode haver perda de capacidade devido à preparação do forno.

A condição de que apenas um tipo de liga pode ser fundida em cada fornada é representada pelas restrições (4.4). 
De (4.5) e (4.7) são indicados os períodos em que haverá custo na preparação do forno. A variável $Z_{k, n}$ é igual a 1 se $Y_{k, n}=1$ e $Y_{k, n-1}=0$, isto é, houve troca de liga de uma fornada para a outra, ou $Z_{k, n}=0$, caso contrário.

As restrições (4.6)-(4.9) representam as condições de utilização e preparação do forno e de produção, estoque e atraso dos itens.

Para a resolução do modelo (4.1)-(4.9) foi aplicada a estratégia de horizonte rolante em conjunto com o método relaxe-e-fixe e um algorito de busca local. Em Araújo et al. (2006) foram estudados três métodos de busca por vizinhança, dos quais o DH (Descent Heuristic) obteve os melhores resultados para os cenários analisados.

Na sequência, será apresentada a estratégia de horizonte rolante e também o método relaxe-e-fixe.

\subsection{Modelo de horizonte rolante}

$\mathrm{Na}$ estratégia de horizonte rolante é proposto que somente as decisões relativas aos períodos imediatos são implementadas, encontrando respostas detalhadas para estes períodos e estimando as decisões nos períodos consecutivos.

$\mathrm{Na}$ prática, a demanda de itens na fundição pode variar de um dia para outro, por exemplo, quando novos pedidos são feitos ou mesmo cancelados. Com o modelo de horizonte rolante, é possível planejar e programar a produção a cada dia e trabalhar com os dados atualizados.

Para que se tenha um modelo de horizonte rolante é necessário modificar a definição das variáveis $Y_{k, n}$ do modelo (4.1)-(4.9):

$Y_{k, n}:$ número de cargas do forno com a liga $k$ no subperíodo $n$.

Desta maneira, podem existir subperíodos em que sejam realizadas mais de uma fornada, sendo necessário modificar também a restrição (4.4) da forma:

$$
\sum_{k=1}^{K} Y_{k, n} \leq \frac{L}{\eta_{t}} \quad t=1, \ldots, T \text { e } n=F_{t}, \ldots, L_{t}
$$

A Figura 4.2 seguinte, mostra como são relacionados os períodos para o método de 
horizonte rolante, considerando $L=10$ fornadas ao dia e horizonte de planejamento de 5 dias $(T=5)$, dos quais um (atual) é dividido em $L$ subperíodos menores e implementado.

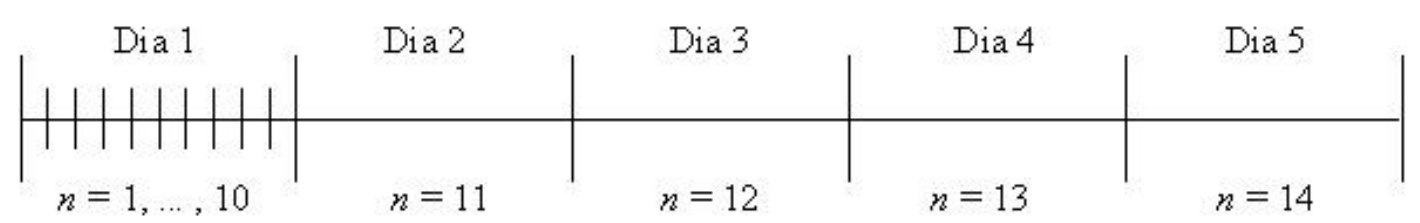

Figura 4.2: Discretização do horizonte de planejamento no método de horizonte rolante.

Para o dia atual será considerado que cada subperíodo $n=1, \ldots, 10$ é capaz de produzir uma carga de forno apenas, enquanto que nos demais dias, podem ser produzidos no máximo $L$ fornadas ao dia. Desta forma, é possível fazer um planejamento de cinco dias de trabalho utilizando apenas 14 subperíodos. Enquanto que, sem a estratégia de horizonte rolante, por sua vez, seriam necessários 50 subperíodos.

As variáveis $Y_{k, n}$ são binárias apenas para $F_{1}, \ldots, L_{1}$. Além disso, as variáveis $Z_{k, n}$ só terão sentido para o primeiro dia de programação, sendo necessário substituir as restrições (4.5) por:

$$
Z_{k, n} \geq Y_{k, n}-Y_{k, n-1} \quad k=1, \ldots, K \text { e } n=F_{1}, \ldots, L_{1}
$$

Para $n=F_{2}, \ldots, L_{T}$ as variáveis $Y_{k, n}$ são consideradas não negativas e inteiras, pois o número de cargas do forno em cada subperíodo pode chegar a $L$.

A partir das considerações anteriores, o seguinte modelo de horizonte rolante é proposto por Araújo et al. (2006):

Minimizar

$$
\sum_{i=1}^{N} \sum_{t=1}^{T}\left(H_{i, t}^{-} I_{i, t}^{-}+H_{i, t}^{+} I_{i, t}^{+}\right)+\sum_{k=1}^{K} \sum_{n=F_{1}}^{L_{1}} s_{k} Z_{k, n}
$$

Sujeito a:

$$
\begin{array}{cl}
I_{i, t-1}^{+}-I_{i, t-1}^{-}+\sum_{n=F_{t}}^{L_{t}} X_{i, n}-I_{i, t}^{+}+I_{i, t}^{-}=d_{i, t} & i=1, \ldots, N \text { e } t=1, \ldots, T \\
\sum_{i \in S(k)} \rho_{i} X_{i, n}+s t_{k} Z_{k, n} \leq \operatorname{cap} Y_{k, n} & k=1, \ldots, K \text { e } n=F_{1}, \ldots, L_{1}
\end{array}
$$




$$
\begin{array}{cl}
\sum_{i \in S(k)} \rho_{i} X_{i, n} \leq \operatorname{cap} Y_{k, n} & k=1, \ldots, K \text { e } n=F_{2}, \ldots, L_{T} \\
\sum_{k=1}^{K} Y_{k, n} \leq \frac{L}{\eta_{t}} & t=1, \ldots, T \text { e } n=F_{t}, \ldots, L_{t} \\
Z_{k, n} \geq Y_{k, n}-Y_{k, n-1} & k=1, \ldots, K \text { e } n=F_{1}, \ldots, L_{1} \\
Y_{k, n} \in\{0,1\} \quad\left(Y_{k, 0}=0\right) & k=1, \ldots, K \text { e } n=F_{1}, \ldots, L_{1} \\
Y_{k, n} \geq 0 \text { e inteiro } & k=1, \ldots, K \text { e } t=F_{2}, \ldots, L_{T} \\
0 \leq Z_{k, n} \leq 1 & k=1, \ldots, K \text { e } n=F_{1}, \ldots, L_{1} \\
X_{i, n} \geq 0 \text { e inteiro } & i=1, \ldots, N \text { e } t=F_{1}, \ldots, L_{1} \\
X_{i, n} \geq 0 & i=1, \ldots, N \text { e } n=F_{2}, \ldots, L_{T} \\
I_{i, t}^{+} \geq 0 \text { e } I_{i, t}^{-} \geq 0 & i=1, \ldots, N \text { e } t=1, \ldots, T .
\end{array}
$$

A solução do modelo (4.11)-(4.22) não é uma solução do problema (4.1)-(4.9). Para obter uma solução para (4.1)-(4.9), o modelo deve ser resolvido cinco vezes (pois foram considerados cinco dias) atualizando os dados a cada resolução.

\subsection{Método relaxe-e-fixe}

Para resolver o modelo de horizonte rolante (4.11)-(4.22), foi aplicado o método relaxe-efixe (Wolsey, 1998).

A estratégia de resolução consiste em duas partes. Num primeiro momento, as variáveis $Y_{k, n}$ para $n=F_{2}, \ldots, L_{T}$ e todas as variáveis $X_{i, n}$, têm sua condição de integralidade relaxada. Este modelo relaxado é resolvido e a solução encontrada indica o valor das variáveis binárias $Y_{k, n}$ em $n=F_{1}, \ldots, L_{1}$ e $k=1, \ldots, K$. O segundo passo consiste em fixar estes valores encontrados e voltar a considerar a integralidade das demais variáveis $Y_{k, n}$ e das variáveis $X_{i, n}$. É obtida uma nova solução factível, que é inteira.

No caso estudado por Araújo (2003), foram obtidos resultados computacionais superiores para o modelo de horizonte rolante aplicado em conjunto com o método relaxee-fixe, em comparação com os resultados obtidos diretamente no modelo de horizonte rolante, com a integralidade das variáveis em questão.

O método relaxe-e-fixe envolve a solução de dois problemas de otimização inteira. O primeiro problema consiste em determinar as variáveis binárias $Y_{k, n}, n=F_{1}, \ldots, L_{1}$, 
e pode ser resolvido pela aplicação de algoritmos de busca local. O segundo problema, consiste em encontrar os valores inteiros para as variáveis $Y_{k, n}$ para $t=F_{2}, \ldots, L_{T}$ e $X_{i, n}$ e pode ser resolvido por uma heurística de arredondamento (Maes et al., 1991). Para a resolução deste último problema foi desenvolvida uma heurística residual que será apresentada no capítulo 6 .

\subsection{Busca local}

Os algoritmos de busca local partem de uma solução factível inicial, que é alterada iterativamente para soluções vizinhas também factíveis, mas com melhor valor para a função objetivo. O algoritmo pára quando algum critério for satisfeito, em geral o número máximo de iterações é atingido.

O algoritmo de busca local aplicado para resolver o primeiro problema decorrente da estratégia relaxe-e-fixe, no modelo de horizonte rolante (4.11)-(4.22), é organizado segundo os seguintes passos:

1. As variáveis binárias $Y_{k, n}, n=F_{1}, \ldots, L_{1}$, são fixadas inicialmente, e as demais restrições de integralidade são relaxadas.

2. O modelo linear resultante é resolvido e a solução encontrada é chamada como solução atual.

3. Os valores das variáveis $Y_{k, n}$ são perturbadas e gerada uma solução nova (solução vizinha).

4. Compara-se a solução atual com a solução nova. Se esta solução nova é melhor que a solução atual, esta última é atualizada (atual recebe a nova solução); caso contrário é determinada outra solução vizinha.

A cada iteração a melhor solução é mantida como solução atual, até que o critério de parada seja satisfeito. Em geral, o número máximo de iterações é atingido, e assim as variáveis $Y_{k, n}\left(t=F_{1}, \ldots, L_{1}\right)$ são fixadas, de acordo com a melhor solução encontrada. 
A solução inicial da primeira etapa do método pode ser calculada e atualizada de diversas formas. Araújo (2003) apresenta três maneiras para obter esta solução inicial e atualizá-la:

1. Para $n=1, \ldots, \eta_{1}$, escolher o valor de $v_{n}$ para ser $k$ com probabilidade dada por $|S(k)| / N$, sendo $|S(k)|$ a cardinalidade do conjunto $S(k)$. Assim, quanto mais itens dependem da liga $k$, mais provável que este $k$ seja selecionado.

2. Utilizar um solver MIP por alguns minutos para obter uma solução inicial.

3. Para $n=1, \ldots, \eta_{1}$, escolher o valor de $v_{n}$ para ser $k$, uniformemente vindas de $\{1, \ldots, K\}$.

O autor opta em trabalhar com a primeira opção, por apresentar melhores resultados. 


\section{Capítulo 5}

\section{Heurísticas de arredondamento}

Métodos heurísticos para a obtenção da solução inteira do problema de corte de estoque podem ser classificados como construtivos e residuais, os quais foram analisados por Poldi (2003). Na sequência serão comentadas as heurísticas residuais aplicadas ao problema de corte de estoque unidimensional, cujos princípios são estendidos para o problema linear inteiro que surge no método relaxe-e-fixe.

Para introduzir as heurísticas residuais de Poldi (2003), serão enunciados o modelo e o problema de corte de estoque.

\subsection{Problema de corte de estoque unidimensional}

O problema de corte de estoque unidimensional inteiro pode ser definido como:

Conside a disponibilidade em estoque de objetos (barras, bobinas etc.) de comprimento L em quantidade suficientemente grande e um conjunto de pedidos, com demanda conhecida $d_{\mathrm{i}}, \mathrm{i}=1, \ldots, \mathrm{m}$, de itens de comprimento $l_{\mathrm{i}}$, $\mathrm{i}=1, \ldots, \mathrm{m}$. O problema consiste em produzir os itens demandados a partir do corte de objetos em estoque, atendendo a demanda de modo a minimizar, por exemplo, a perda de material. (Poldi, 2003)

Durante a década de 60, estudos expressivos nesta área foram realizados por Gilmore e Gomory, que apresentaram o método simplex com geração de colunas para um modelo de otimização linear, encontrando uma solução aproximada para problemas grandes de corte unidimensional. 
Este modelo é baseado na determinação da frequência com que os objetos são cortados segundo um padrão de corte (um padrão de corte é a maneira particular na qual um objeto é cortado).

A modelagem matemática de um problema de corte de estoque é realizada em duas etapas:

1. Definir todos os possíveis padrões de corte.

2. Determinar quantas vezes cada padrão de corte é utilizado para que a demanda seja atendida

A cada padrão de corte é associado um vetor m-dimensional:

$$
\mathbf{a}=\left(\alpha_{1}, \alpha_{2}, \ldots, \alpha_{m}\right),
$$

em que $\alpha_{i}$ é a quantidade de itens do tipo $i$ no padrão de corte.

No modelo apresentado na sequência, são considerados vários tipos de barras em estoque e em quantidade limitada.

As seguintes definições são utilizadas no problema:

Índices:

$i=1, \ldots, m:$ tipos de itens;

$j=1, \ldots, N$ : número de padrões de corte.

Dados do problema:

$l_{i}: \quad$ comprimento do item $i$

$d_{i}: \quad$ demanda do item $i$

$\mathbf{a}_{j}$ : $\quad$ vetor correspondente ao padrão de corte $j$;

$c_{j}$ : custo de cortar um objeto segundo o padrão de corte $j$ (por exemplo, a perda).

Variável de decisão:

$x_{j}$ : número de objetos cortados usando o padrão de corte $j$. 
Formulação do problema:

Minimizar

$$
\sum_{j=1}^{N} c_{j} x_{j}
$$

Sujeito a:

$$
\begin{aligned}
& \sum_{j=1}^{N} \mathbf{a}_{j} x_{j}=\mathbf{d} \\
& x_{j} \geq 0 \text { e inteiro } j=1, \ldots, N .
\end{aligned}
$$

A função objetivo (5.2) minimiza o custo total, que pode ser a perda total. A restrição (5.3) estabelece que a quantidade de itens produzidos seja exatamente igual a demanda, e (5.4) garante que o número de vezes que um objeto é cortado conforme o padrão $j$ seja inteiro e não-negativo.

A condição de integralidade das variáveis $x_{j}$ torna o problema difícil de ser resolvido. Uma abordagem prática para contornar este problema é relaxar a condição de integralidade e resolver o problema pelo método simplex utilizando um processo de geração de colunas. Em seguida são utilizados alguns métodos heurísticos para o arredondamento desta solução. As idéias aqui utilizadas serão consideradas para obtenção de valores inteiros para as variáveis de produção no problema de dimensionamento de lotes para pequenas fundições.

\subsection{Heurísticas residuais}

As heurísticas que serão apresentadas em seguida geram uma solução inteira para o problema de corte de estoque unidimensional inteiro.

Para facilitar o estudo sobre o problema (5.2)-(5.4), é usada a forma matricial:

Minimizar

$$
\sum_{j=1}^{n} c_{j} x_{j}
$$

Sujeito a:

$$
\begin{aligned}
& \mathbf{A} \mathbf{x}=\mathbf{d} \\
& \mathbf{x} \geq 0 \text { e inteiro. }
\end{aligned}
$$


No problema (5.5)-(5.7) a integralidade das variáveis $x_{j}$, para todo $j$ é relaxada e o modelo é resolvido pelo método simplex aplicando o método de geração de colunas. Supondo que nesta solução ótima encontrada $\tilde{\mathbf{x}}$, ao menos uma componente da solução não é inteira, é aplicada então uma heurística residual para obter a solução inteira.

Definimos $\tilde{\mathbf{y}}$ como uma solução inteira aproximada para $\tilde{\mathbf{x}}$, como uma solução de coordenadas inteiras (em certo sentido $\tilde{\mathbf{y}} \cong \tilde{\mathbf{x}}$ ) tal que

$$
\mathbf{A} \tilde{\mathbf{y}} \leq \mathbf{d}
$$

Um exemplo simples de uma solução inteira aproximada é dada por:

$$
\tilde{y}_{i}=\left\lfloor\tilde{x}_{i}\right\rfloor \quad i=1, \ldots, m .
$$

Poldi (2003) utiliza outros procedimentos para obtenção da solução inteira aproximada. O vetor $\mathbf{r}=\mathbf{d}-\mathbf{A} \tilde{\mathbf{y}}$ define a demanda residual e o problema (5.5)-(5.7) é novamente resolvido para esta nova demanda e uma nova solução inteira aproximada obtida. Como a demanda torna-se baixa, os padrões de corte gerados (colunas em (5.6)) são restritos, isto é, o número de itens em cada padrão de corte é limitado pela demanda residual. Este processo é repetido enquanto houver demanda residual ou até que a solução inteira aproximada seja nula (neste caso, um problema residual, em geral com poucos itens demandados, é resolvido à parte. Os procedimentos de arredondamento desenvolvidos por Poldi evitam esta situação). 


\section{Capítulo 6}

\section{Modelo e método de solução}

\section{proposto}

O modelo proposto para a análise de dados é baseado no modelo de horizonte rolante de Araújo et al. (2006), sendo, no entanto, desconsiderados os tempos de preparação. Para a resolução deste modelo é proposta a aplicação de uma estratégia relaxe-e-fixe utilizando o método de busca local e heurísticas residuais.

\subsection{Modelo de horizonte rolante para um PDL mo- noestágio}

As definições deste modelo são as mesmas apresentadas na sessão 4.1, exceto a definição das variáveis de tempo de peparação, que não serão consideradas no modelo seguinte.

Formulação do problema HR:

Minimizar

$$
\sum_{i=1}^{N} \sum_{t=1}^{T}\left(H_{i, t}^{-} I_{i, t}^{-}+H_{i, t}^{+} I_{i, t}^{+}\right)+\sum_{k=1}^{K} \sum_{n=F_{1}}^{L_{1}} s_{k} Z_{k, n}
$$

Sujeito a:

$$
\begin{array}{cl}
I_{i, t-1}^{+}-I_{i, t-1}^{-}+\sum_{n=F}^{L_{t}} X_{i, n}-I_{i, t}^{+}+I_{i, t}^{-}=d_{i, t} & i=1, \ldots, N \text { e } t=1, \ldots, T \\
\sum_{i \in S(k)} \rho_{i} X_{i, n} \leq \operatorname{cap} Y_{k, n} & k=1, \ldots, K \text { e } n=F_{1}, \ldots, L_{T} \\
\sum_{k=1}^{K} Y_{k, n} \leq \frac{L}{\eta_{t}} & t=1, \ldots, T \text { e } n=F_{t}, \ldots, L_{t}
\end{array}
$$




$$
\begin{array}{cl}
Z_{k, n} \geq Y_{k, n}-Y_{k, n-1} & k=1, \ldots, K \text { e } n=F_{1}, \ldots, L_{1} \\
Y_{k, n} \in\{0,1\} \quad\left(Y_{k, 0}=0\right) & k=1, \ldots, K \text { e } n=F_{1}, \ldots, L_{1} \\
Y_{k, n} \geq 0 \text { e inteiro } & k=1, \ldots, K \text { e } n=F_{2}, \ldots, L_{T} \\
Z_{k, n} \geq 0 & k=1, \ldots, K \text { e } n=F_{1}, \ldots, L_{1} \\
X_{i, n} \geq 0 \text { e inteiro } & i=1, \ldots, N \text { e } n=F_{1}, \ldots, L_{1} \\
X_{i, n} \geq 0 & i=1, \ldots, N \text { e } n=F_{2}, \ldots, L_{T} \\
I_{i, t}^{+} \geq 0 \text { e } I_{i, t}^{-} \geq 0 & i=1, \ldots, N \text { e } t=1, \ldots, T .
\end{array}
$$

\section{Cálculo dos custos de estoque e atraso}

Seja $\alpha_{i}$ a quantidade de dias que o item $i$ está atrasado, quando $t=0$. Desta forma, se o item $i$ deve ser entregue no dia $1, \alpha_{i}=0$ (nenhum dia de folga), caso o item $i$ deva ser entregue no dia $2, \alpha_{i}=-1$ (tendo um dia de folga antes de ser entregue). Os valores de $\alpha_{i}$ podem ser representados da forma:

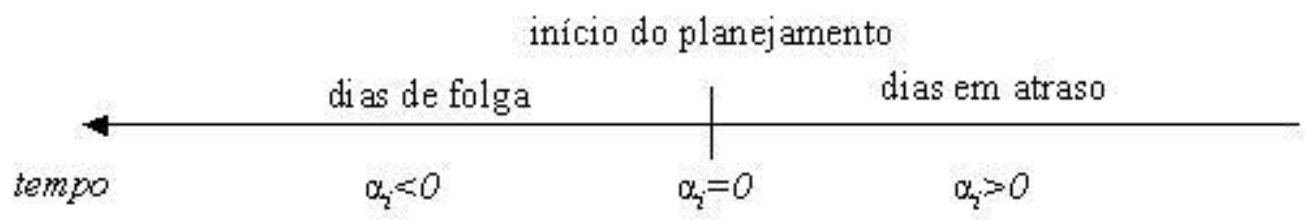

O valor de $\alpha_{i}$ é utilizado para calcular os custos de estoque e atraso, lembrando que um objetivo do problema é minimizar os atrasos na entrega dos itens. Neste sentido, os custos são calculados da seguinte maneira:

$$
\begin{gathered}
\text { Se } \quad \alpha_{i} \geq 0 \text { então } H_{i, t}^{-}=\rho_{i}\left(\alpha_{i}+t\right) \text { e } H_{i, t}^{+}=G \\
\text { senão }\left\{\begin{array}{r}
\text { se } t=1, \ldots,\left|\alpha_{i}\right| \Rightarrow H_{i, t}^{-}=G \text { e } H_{i, t}^{+}=\rho_{i} \\
\text { se } t=1+\left|\alpha_{i}\right|, \ldots, T \Rightarrow H_{i, t}^{-}=\rho_{i}\left(\alpha_{i}+t\right) \text { e } H_{i, t}^{+}=G .
\end{array}\right.
\end{gathered}
$$

Quando $\alpha_{i} \geq 0$, ou seja, a entrega do item $i$ está atrasada, ou ainda, que a entrega seja para o dia atual (quando $\alpha_{i}=0$ ), faz-se com que $H_{i, t}^{+}$seja G (número grande) e também com que o custo de atraso aumente com o passar dos dias. 
No caso em que $\alpha_{i}<0$, a entrega do item $i$ não está atrasada. No decorrer dos dias, enquanto existem dias de folga até o dia de entrega, são atribuidos custos de estoque e atraso de forma que $H_{i, t}^{-}$seja G. Por outro lado, quando calculada a produção para o dia da entrega do item, ou aos dias posteriores (o que já representa atraso da entrega), o custo de atraso aumenta conforme os dias $\rho_{i}\left(\alpha_{i}+t\right)$.

Devido à definição de $\alpha_{i}$, se o pedido de um item tem diferentes datas de entrega, então este item é considerado como itens distintos na carteira de pedidos, tendo cada um deles um valor de $\alpha_{i}$ correspondente. Embora isto provoque um aumento no problema em termos de variáveis e restrições, não é significativo para dados práticos, pois a ocorrência é baixa.

\subsection{Método de solução para HR}

Considerando o modelo HR anterior, o primeiro passo do método consiste em aplicar uma estratégia relaxe-e-fixe sugerida em Araújo (2003), relaxando a integralidade nas restrições (6.7) e (6.9) do modelo HR, obtendo assim, um novo modelo que será chamado como HR-R.

Na etapa seguinte é aplicado o método de busca local, na qual, são analisadas soluções vizinhas, para que sejam fixados os valores binários das variáveis $Y_{k, n}$ referentes ao primeiro dia.

Para isto, é definido um vetor $\mathbf{v}=\left[v_{n}\right]$ para representar qual o tipo de liga produzida em cada subperíodo (lembrando que é considerado apenas o dia 1 e, portanto, $\left.n=F_{1}, \ldots, L_{1}\right)$, ou seja, se $v_{n}=k$ então a liga $k$ é produzida na fornada $n$, o que corresponde a $Y_{k, n}=1$. Por exemplo, se $v=[2,1,1, \ldots, 2]$, então o $v_{1}=2$, significa que a liga 2 é produzida no subperíodo 1 , ou seja, $Y_{2,1}=1$ enquanto que $Y_{k, 1}=0$ para todo $k \neq 2$.

Há várias maneiras de encontrar um vetor $\mathbf{v}$ inicial, uma delas é resolvendo um modelo de planejamento das ligas (Tonaki, 2006), como descrito nas sessões (3.2.1) e $(3.3 .1)$.

Os valores $A_{k, 1}$ com $k=1, \ldots, K$ encontrados pela resolução do modelo (3.5)-(3.11) representam o número de vezes que a liga $k$ é fundida no dia 1. A partir destes valores é encontrado o vetor v. Suponha, por exemplo, que sejam encontrados os seguintes valores 
para $A_{k, 1}$, num problema com 3 tipos de ligas:

$$
A_{1,1}=2, \quad A_{2,1}=3 \text { e } A_{3,1}=5
$$

em que, no primeiro dia são utilizadas 2 fornadas para a liga 1, 3 fornadas para a liga 2 e 5 fornadas com a liga 3, num total de 10 fornadas no dia. Assim é possível obter o vetor $\mathbf{v}$ de diversas maneiras, como por exemplo:

$$
\mathbf{v}=(1,1,2,2,2,3,3,3,3,3)
$$

$\mathrm{Ou}$

$$
\mathbf{v}=(2,2,2,1,1,3,3,3,3,3)
$$

Outros vetores correspondentes podem ser encontrados, mas é importante estabelecer que as fornadas de mesma liga permaneçam agrupadas, evitando custos de preparação desnecessários.

Araújo(2003) estudou outras formas de encontrar os elementos do vetor v. Uma delas é atribuir $v_{n}=k$ com probabilidade dada por $\left(D_{k, 1} / N\right)$, em que, $D_{k, 1}$ é a demanda da liga $k$ (em $\mathrm{kg}$ ) no primeiro dia e $N$ os tipos de itens na programação. Assim, quanto mais produtos (em kg) podem ser feitos da liga $k$ no dia da programação, mais provável que a liga k seja selecionada.

Encontrado o vetor $\mathbf{v}$, as variáveis binárias $Y_{k, n}$ para $k=1, \ldots, K$ e $n=F_{1}, \ldots, L_{1}$ são fixados no modelo HR-R, resultando no modelo linear HR-RF.

Formulação do problema HR-RF:

Minimizar

$$
\sum_{i=1}^{N} \sum_{t=1}^{T}\left(H_{i, t}^{-} I_{i, t}^{-}+H_{i, t}^{+} I_{i, t}^{+}\right)
$$

Sujeito a:

$$
\begin{array}{cl}
I_{i, t-1}^{+}-I_{i, t-1}^{-}+\sum_{n=F_{t}}^{L_{t}} X_{i, n}-I_{i, t}^{+}+I_{i, t}^{-}=d_{i, t} & i=1, \ldots, N \text { e } t=1, \ldots, T \\
\sum_{i \in S\left(v_{n}\right)} \rho_{i} X_{i, n} \leq c a p & n=F_{1}, \ldots, L_{1} \\
\sum_{i \in S(k)} \rho_{i} X_{i, n} \leq \operatorname{cap} Y_{k, n} & k=1, \ldots, K \text { e } n=F_{2}, \ldots, L_{T} \\
\sum_{k=1}^{K} Y_{k, n} \leq \frac{L}{\eta_{t}} & t=1, \ldots, T \text { e } n=F_{t}, \ldots, L_{t}
\end{array}
$$




$$
\begin{array}{cl}
Y_{k, n} \geq 0 & k=1, \ldots, K \text { e } n=F_{2}, \ldots, L_{T} \\
X_{i, n} \geq 0 & i=1, \ldots, N \text { e } n=F_{1}, \ldots, L_{T} \\
I_{i, t}^{+} \geq 0 \text { e } I_{i, t}^{-} \geq 0 & i=1, \ldots, N \text { e } t=1, \ldots, T .
\end{array}
$$

A função objetivo (6.12) do modelo HR-RF não penaliza o problema com custos de preparação. Como estes custos são constantes para cada vetor v analisado, eles são calculados e depois adicionados ao valor mínimo encontrado para a função objetivo. Desta forma, é definido:

$$
f_{\text {atual }}=\sum_{i=1}^{N} \sum_{t=1}^{T}\left(H_{i, t}^{-} I_{i, t}^{-}+H_{i, t}^{+} I_{i, t}^{+}\right)+\sum_{n=F_{1}}^{L_{1}}\left(s_{v_{n}} Z_{v_{n}, n}\right)
$$

o valor da função objetivo para o modelo $\mathrm{HR}$, em que, o valor de $Z_{v_{n}, n}$ é calculado da forma:

$$
\begin{gathered}
\text { Se } v_{n-1}=v_{n} \text { então } Z_{v_{n}, n}=0 \\
\text { senão }\left\{\begin{array}{r}
\text { se } v_{n}=0 \Rightarrow Z_{v_{n}, n}=0 \\
\text { se } v_{n} \neq 0 \Rightarrow Z_{v_{n}, n}=1
\end{array}\right.
\end{gathered}
$$

considerando $v_{0}=0$ e $v_{n}=0$ significa que na fornada $n$ não houve produção.

Foi encontrada, portanto, uma soluçao factível inicial para o modelo HR-R.

A partir desta solução inicial são analisadas novas soluções vizinhas, encontrando, após 500 iterações, os valores das variáveis $Y_{k, n} \geq 0$ correspondentes a melhor solução verificada. Cada iteração consiste em:

- Considere o vetor $v=\left[v_{n}\right]$ para $n=F_{1}, \ldots, L_{1}$, encontrado anteriormente. Selecionase um subperíodo $j, F_{1} \leq j \leq L_{1}$, e uma liga $l, 1 \leq l \leq K$. Faça $v_{j}=l$, encontrando assim um novo vetor $\mathbf{v}$, que será chamado $\mathbf{v}_{\text {nova }}$. Desta forma, $Y_{l, j}=1$ e $Y_{k, j}=0$ para todo $k \neq j$.

- Fixa $\mathbf{v}_{\text {nova }}$ em HR-R, e resolva HR-RF resultante e calcule

$$
f_{\text {nova }}=\sum_{i=1}^{N} \sum_{t=1}^{T}\left(H_{i, t}^{-} I_{i, t}^{-}+H_{i, t}^{+} I_{i, t}^{+}\right)+\sum_{n=F_{1}}^{L_{1}}\left(s_{v_{n}} Z_{v_{n}, n}\right) .
$$


- Atualização:

$$
\text { Se } f_{\text {nova }}<f_{\text {atual }} \text {, faça } f_{\text {atual }}=f_{\text {nova }} \text { e } \mathbf{v}=\mathbf{v}_{\text {nova }} \text {. }
$$

Assim, a melhor entre as duas soluções é armazenada e inicia-se a análise de nova solução vizinha, enquanto $I T \leq 500$.

Até esta etapa foram encontrados os valores das variáveis:

- $Y_{k, n}$ binárias, para $k=1, \ldots, K$ e $n=F_{1}, \ldots, L_{1}$;

- $Y_{k, n} \geq 0$ e contínuo, para $k=1, \ldots, K$ e $n=F_{2}, \ldots, L_{T}$;

- $X_{i, n} \geq 0$ e contínuo, para $i=1, \ldots, N$ e $n=F_{1}, \ldots, L_{T}$.

Com o intuito de encontrar $X_{i, n} \geq 0$ e inteiro para o dia 1, é aplicada uma estratégia de arredondamento, como mostrado na sequencia.

As variáveis $X_{i, n}$ para $i=1, \ldots, N$ e $n=F_{1}, \ldots, L_{1}$, referentes à melhor solução encontrada pela busca local, é arredondada da forma:

$$
\tilde{X}_{i, n}=\left\lfloor X_{i, n}\right\rfloor
$$

Quando estas variáveis de produção são arredondadas para o seu menor inteiro, as quantidades de estoque e atraso também são modificadas, observando que, quando existe uma quantidade de itens $i$ em atraso, após o arredondamento esta quantidade de atraso aumenta, de forma contrária, se havia alguma quantidade deste item em estoque, esta quantidade diminuiu.

É necessário, portanto, após o arredondamento das variáveis de produção $X_{i, n}$ do primeiro dia, atualizar as variáveis de estoque e atraso $I_{i, t}^{+}$e $I_{i, t}^{-}, \forall i, t$. Para isso serão considerados:

$\tilde{I}_{i, t}^{-}:$quantidade atualizada de itens $i$ em atraso no período $t$

$\tilde{I}_{i, t}^{+}$: quantidade atualizada de itens $i$ em estoque no período $t$;

$\tilde{I}_{i, 0}^{-}=I_{i, 0}^{-}$e $\tilde{I}_{i, 0}^{+}=I_{i, 0}^{+}$.

A atualização é feita de forma que:

$$
\tilde{I}_{i, t}=d_{i, t}-\sum_{n=F_{t}}^{L_{t}} \tilde{X}_{i, n}-\tilde{I}_{i, t-1}^{+}+\tilde{I}_{i, t-1}^{-},
$$




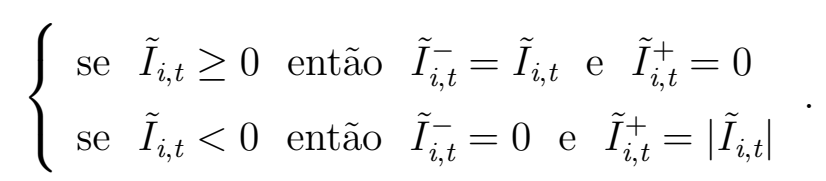

Além da alteração nas variáveis referentes ao estoque e atraso, é possível verificar mudanças nos valores que indicam a capacidade utilizada do forno. Um pensamento lógico vem de que, quando as variáveis de produção são arredondadas para o menor inteiro, diminui-se a produção dos itens e, consequentemente, a produção, em peso, das ligas correspondentes.

Considere novamente as restrições de capacidade do forno no primeiro dia, em que os valores binários de $Y_{k, n}, n=F_{1}, \ldots, L_{1}$, já são conhecidos.

Quando $Y_{k, n}=0$, sabe-se que $X_{i, n}=0, \forall i \in S(k)$, pois, se não é produzida uma liga no subperíodo, não é possível produzir os itens que dependem dela neste subperíodo.

Analisando os casos em que $Y_{k, n}=1$ (isto é, $v_{n}=k$ ), a restrição de capacidade do forno para o primeiro dia é dada por:

$$
\sum_{i \in S\left(v_{n}\right)} \rho_{i} X_{i, n} \leq \operatorname{cap} \quad n=F_{1}, \ldots, L_{1}
$$

Quando ocorre o arredondamento $\tilde{X}_{i, n}=\left\lfloor X_{i, n}\right\rfloor$ surge uma capacidade residual para o subperíodo $n$, que pode ser expressa por:

$$
c a p_{n}=c a p-\sum_{i \in S\left(v_{n}\right)} \rho_{i} \tilde{X}_{i, n}
$$

a qual, pode ser utilizada por itens $i \in S\left(v_{n}\right)$ tais que $\rho_{i} \leq \operatorname{cap}_{n}$. Adotamos ainda outro critério a ser satisfeito pelo item, $\tilde{I}_{i, 1}^{-}>0$, ou seja, há quantidade atrasada deste item no final do primeiro dia.

A próxima etapa do método de solução trabalha no sentido de utilizar esta capacidade residual do forno em cada um dos suberíodos do primeiro dia.

O conjunto dos itens candidatos a preencher a fornada $n$ é dado por:

$$
A=\left\{i \text { tal que } i \in S\left(v_{n}\right), \tilde{I}_{i, 1}^{-}>0 \text { e } \rho_{i} \leq c a p_{n}\right\}
$$

É necessário agora, saber a melhor forma de organizar os itens $i \in A$ para que seja desperdiçado o mínimo possível de espaço no forno. Neste sentido é aplicado o problema da mochila. 
Considere a variável residual:

$a_{i}$ : a quantidade do item $i$ a ser produzida utilizando a $c a p_{n}, i \in A$.

Assim, o preenchimento da capacidade residual na fornada $n$ é obtida pela solução do problema da mochila:

Minimizar

$$
\sum_{i \in A} \rho_{i} a_{i}
$$

Sujeito a:

$$
\begin{gathered}
\sum_{i \in A} \rho_{i} a_{i} \leq \operatorname{cap}_{n} \\
0 \leq a_{i} \leq \tilde{I}_{i, 1}^{-} \text {e } a_{i} \text { inteiro } \forall i \in A .
\end{gathered}
$$

Com este acréscimo $a_{i}$ na produção do item $i$, é necessário atualizar os valores de produção, estoque e capacidade residual para $i \in A$, da forma:

$$
\begin{gathered}
\tilde{X}_{i, n}=\tilde{X}_{i, n}+a_{i} ; \\
\tilde{I}_{i, t}=d_{i, t}-\sum_{n=F_{1}}^{L_{1}} \tilde{X}_{i, n}-\tilde{I}_{i, t-1}^{+}+\tilde{I}_{i, t-1}^{-}, \quad \text { obedecendo (6.20); } \\
\operatorname{cap}_{n}=\operatorname{cap}-\sum_{i \in S\left(v_{n}\right)} \rho_{i} \tilde{X}_{i, n} .
\end{gathered}
$$

Após a aplicação desta heurística residual em todos os subperíodos do primeiro dia, resta atualizar o estoque para os dias consecutivos, ou seja, para $n=F_{2}, \ldots, L_{T}$ :

$$
\tilde{I}_{i, t}=d_{i, t}-\sum_{n=F_{t}}^{L_{t}} \tilde{X}_{i, n}-\tilde{I}_{i, t-1}^{+}+\tilde{I}_{i, t-1}^{-},
$$

obedecendo (6.20).

Após realizado este processo de solução, são encontrados os seguintes resultados:

- $Y_{k, n}$ binárias, para $k=1, \ldots, K$ e $n=F_{1}, \ldots, L_{1}$;

- $Y_{k, n} \geq 0$ e contínuo, para $k=1, \ldots, K$ e $n=F_{2}, \ldots, L_{T}$;

- $X_{i, n} \geq 0$ e inteiro, para $i=1, \ldots, N$ e $n=F_{1}, \ldots, L_{1}$;

- $X_{i, n} \geq 0$ e contínuo, para $i=1, \ldots, N$ e $n=F_{2}, \ldots, L_{T}$. 


\subsection{Extensão da abordagem proposta}

Seja o modelo (horizonte rolante):

Minimizar

$$
c^{T}(z, w)+d^{T} y
$$

Sujeito a:

$$
\begin{gathered}
A(z, w)+B y=a \\
C z \leq b \\
z \geq 0 \text { e inteiro } \\
y \in\{0,1\} \\
w \geq 0 .
\end{gathered}
$$

O procedimento de solução pode ser dividido em duas etapas, na primeira fixa-se $y \in\{0,1\}$

a partir do modelo relaxado. Na segunda etapa, arredonda-se $z$ e atualiza $w$.

Procedimento - etapa 1: (retorna $y_{\text {atual }} \in\{0,1\}$ e $x_{\text {atual }} \in \Re^{+}$)

1. Encontra $y_{\text {atual }}$ inicial. $f_{\text {atual }}=\infty . I T=0 . y_{\text {nova }}=y_{\text {atual }}$.

2. Resolve:

$$
\begin{gathered}
\text { Minimizar } f^{r}(x)=c^{T} x+d^{T} y_{\text {nova }} \\
\text { Sujeito } a: A x=a-B y_{\text {nova }} \text { e } x \geq 0,
\end{gathered}
$$

e encontra $x_{\text {nova }}$.

3. Se $f_{\text {atual }}>f\left(x_{\text {nova }}, y_{\text {nova }}\right)$ então:

$$
\begin{gathered}
f_{\text {atual }}=f\left(x_{\text {nova }}, y_{\text {nova }}\right) \\
x_{\text {atual }}=x_{\text {nova }} \\
y_{\text {atual }}=y_{\text {nova }} .
\end{gathered}
$$

4. $I T=I T+1$. Se $I T<I T \_M A X$ então, determine um vizinho de $y_{\text {atual }}$ e obtenha $y_{\text {nova }}$ e vá para 2 . 
Procedimento - etapa 2: (retorna $\left.z_{\text {atual }} \in \Re^{+}\right)$

1. Seja $x_{\text {atual }}=\left(z_{\text {atual }}, w_{\text {atual }}\right) . z_{\text {atual }}=\left\lfloor z_{\text {atual }}\right\rfloor$, que satisfaz $C z_{\text {atual }} \leq b$ com $C \geq 0$.

2. Determina $r$, tal que:

$$
\text { Maximize } f^{m}(r)=\Theta^{T} r
$$

Sujeito a: $D r \leq b-C z_{\text {atual }}, z_{\text {atual }}=r+z_{\text {atual }}$ e $r \geq 0$,

em que, $\Theta$ é o retorno por incrementar $z_{\text {atual }}$. No problema estudado $\Theta^{T}=D$.

3. Determina $w_{\text {atual }}$, tal que $A\left(z_{\text {atual }}, w_{\text {atual }}\right)+B y_{\text {atual }}=a$.

Fim: ( $\left.y_{\text {atual }}, z_{\text {atual }}, w_{\text {atual }}\right)$. 


\section{Capítulo 7}

\section{Experimentos computacionais}

Para testar o método de solução proposto neste trabalho é elaborado um gerador de dados que constrõe três tamanhos diferentes de problemas. Num segundo momento, são gerados problemas variando o número de itens, o número de ligas e a quantidade de itens em atraso, e analisado o comportamento do método para estas variações.

Para a realização destes testes foi utilizado um Pentium 4, 2.8GHz com 512 MB de memória RAM e o pacote CPLEX 10.0.

\subsection{Geração dos dados}

São definidos três tipos de problemas, o pequeno, o médio e o grande, gerados a partir dos parâmetros apresentados na Tabela 7.1.

O sorteio dos elementos $\alpha_{i}$ é feito de forma que em torno de $20 \%$ dos $N$ tipos de itens estejam atrasados, ou seja, neste caso $\alpha_{i}>0$.

A demanda é gerada de forma que $20 \%$ dela em kg esteja atrasada, ou seja, estes $20 \%$ da demanda estão relacionados aos valores $\alpha_{i}>0$ já gerados.

A capacidade total em $\mathrm{kg}$ nos 5 dias de planejamento, para 10 fornadas ao dia, equivale a $18000 \mathrm{~kg}$. Nos problemas gerados é admitida uma demanda total em torno de $21600 \mathrm{~kg}$ na semana, sendo $4320 \mathrm{~kg}$ de demanda atrasada.

Foram gerados 10 problemas para cada tipo, pequeno, médio e grande, e foram calculados a qualidade da solução e o tempo computacional. A solução destes problemas corresponde à solução do problema inteiro misto. 


\begin{tabular}{c|c}
\hline Parâmetros & Valores \\
\hline \hline Número de itens & Pequeno: 10 \\
& Médio: 50 \\
Número de ligas & Grande: 100 \\
\hline Número de dias & Pequeno: 2 \\
\hline Capacidade (kg) do forno & Médio: 10 \\
\hline Número de fornadas ao dia & Grande: 20 \\
\hline Penalidade de setup & 5 \\
\hline Dias de atraso & 360 \\
\hline Peso do item & 10 \\
\hline \hline
\end{tabular}

Tabela 7.1: Parâmetros utilizados pelo gerador.

\subsection{Resultados computacionais}

A análise da qualidade das soluções apresentada a seguir foi feita com base na média dos 10 problemas gerados para cada tipo de problema.

Uma solução é considerada ótima se está a menos de $1 \%$ do limitante inferior. Para os problemas pequenos, o Cplex 10.0 conseguiu encontrar a solução ótima para 2 dos 10 exemplos. Nos problemas médios e grandes não foi encontrada nenhuma solução ótima, nestes casos, o limite de tempo fixado em 1200 segundos foi alcançado antes da otimalidade e a melhor solução factível encontrada é considerada.

Considere:

$\operatorname{Lim}_{C}:$ limitante inferior encontrado pelo Cplex;

$S_{C}$ : valor da função objetivo para a melhor solução encontrada pelo Cplex;

$S_{H} l_{H}$ valor da função objetivo para a solução encontrada pela heurística proposta.

A qualidade da solução do pacote Cplex $\left(G a p_{C}\right)$, bem como do método heurístico apresentado $\left(G a p_{H}\right)$ é avaliada em relação ao limitante inferior encontrado pelo Cplex. 
Desta forma,

$$
\begin{aligned}
\operatorname{Gap}_{C} & =\frac{\text { Sol }_{C}-\operatorname{Lim}_{C}}{\operatorname{Sol}_{C}} .100, \\
\operatorname{Gap}_{H} & =\frac{\text { Sol }_{H}-\operatorname{Lim}_{C}}{\operatorname{Sol}_{H}} .100 .
\end{aligned}
$$

Os valores da função objetivo dos problemas gerados são apresentados nas Tabelas $(7.2)-(7.4)$

\begin{tabular}{|c|c|c|c|c|c|c|c|}
\hline Problema & Sol $_{C}$ & Lim $_{C}$ & Gap $_{C}(\%)$ & $T_{C}(\mathrm{seg})$ & $\operatorname{Sol}_{H}$ & Gap $_{H}(\%)$ & $T_{H}(\mathrm{seg})$ \\
\hline \hline 1 & 52454,00 & 52320,15 & 0,26 & 1200,00 & 60599,00 & 13,66 & 14,00 \\
\hline 2 & 23891,00 & 23577,39 & 1,31 & 1200,00 & 25724,00 & 8,34 & 14,00 \\
\hline 3 & 18438,00 & 18423,00 & 0,08 & 1200,00 & 20305,00 & 9,27 & 13,00 \\
\hline 4 & 41513,00 & 41506,23 & 0,02 & 1200,00 & 42752,00 & 2,91 & 13,00 \\
\hline 5 & 14413,00 & 14411,94 & 0,01 & 0,78 & 16188,00 & 10,97 & 13,00 \\
\hline 6 & 21168,00 & 20884,21 & 1,34 & 1200,00 & 21741,00 & 3,94 & 13,00 \\
\hline 7 & 17171,00 & 17064,17 & 0,62 & 1200,00 & 18019,00 & 5,30 & 13,00 \\
\hline 8 & 34798,00 & 34639,58 & 0,46 & 1200,00 & 35317,00 & 1,92 & 13,00 \\
\hline 9 & 44993,00 & 44822,14 & 0,38 & 1200,00 & 46735,00 & 4,09 & 13,00 \\
\hline 10 & 15791,00 & 15789,64 & 0,01 & 1,17 & 16685,00 & 5,37 & 13,00 \\
\hline Média & & & 0,45 & 960,20 & & 6,58 & 13,20 \\
\hline
\end{tabular}

Tabela 7.2: Solução dos problemas pequenos.

As colunas $T_{C}(\mathrm{seg})$ e $T_{H}(\mathrm{seg})$ representam, respectivamente, o tempo computacional do pacote Cplex e da heurística proposta, em segundos.

Avaliando o desempenho do método heurístico em relação ao pacote Cplex é possível observar que, este último, obteve melhor desempenho nas três classes, pequeno, médio e grande. Assim como no Cplex, no método heurístico o gap aumenta com o tamanho dos problemas, como mostra o gráfico da Figura 7.1.

Estes problemas também foram resolvidos pelo pacote Cplex 7.5, que por sua vez, obteve bons resultados apenas para os problemas pequenos, com gap médio de 3,51\% sendo duas soluções ótimas. Para os problemas médios, seu desempenho em relação aos resultados obtidos pelo Cplex 10.0 e o método heurístico é bastante inferior, sendo que 


\begin{tabular}{|c|c|c|c|c|c|c|c|}
\hline Problema & Sol $_{C}$ & $\operatorname{Lim}_{C}$ & $\operatorname{Gap}_{C}(\%)$ & $T_{C}(\mathrm{seg})$ & $\operatorname{Sol}_{H}$ & Gap $_{H}(\%)$ & $T_{H}(\mathrm{seg})$ \\
\hline \hline 1 & 18423,00 & 16763,62 & 9,01 & 1200,00 & 21003,00 & 20,18 & 48,00 \\
\hline 2 & 12503,00 & 11041,28 & 11,69 & 1200,00 & 13766,00 & 19,79 & 47,00 \\
\hline 3 & 20683,00 & 18641,56 & 9,87 & 1200,00 & 22502,00 & 17,16 & 48,00 \\
\hline 4 & 19840,00 & 18127,54 & 8,63 & 1200,00 & 20569,00 & 11,87 & 47,00 \\
\hline 5 & 11551,00 & 9714,73 & 15,90 & 1200,00 & 12531,00 & 22,47 & 48,00 \\
\hline 6 & 36807,00 & 33234,70 & 9,71 & 1200,00 & 37040,00 & 10,27 & 53,00 \\
\hline 7 & 11861,00 & 9868,78 & 16,80 & 1200,00 & 13129,00 & 24,83 & 48,00 \\
\hline 8 & 26233,00 & 23919,84 & 8,82 & 1200,00 & 27488,00 & 12,98 & 52,00 \\
\hline 9 & 24500,00 & 22184,44 & 9,45 & 1200,00 & 26384,00 & 15,92 & 51,00 \\
\hline 10 & 20804,00 & 19289,60 & 7,28 & 1200,00 & 21827,00 & 11,63 & 49,00 \\
\hline Média & & & 10,71 & 1200,00 & & 16,71 & 49,10 \\
\hline
\end{tabular}

Tabela 7.3: Solução dos problemas médios.

\begin{tabular}{|c|c|c|c|c|c|c|c|}
\hline Problema & Sol $_{C}$ & Lim $_{C}$ & Gap $_{C}(\%)$ & $T_{C}(\mathrm{seg})$ & $\operatorname{Sol}_{H}$ & Gap $_{H}(\%)$ & $T_{H}(\mathrm{seg})$ \\
\hline \hline 1 & 22341,00 & 17514,73 & 21,60 & 1200,00 & 24487,00 & 28,47 & 120,00 \\
\hline 2 & 25122,00 & 18901,12 & 24,76 & 1200,00 & 25781,00 & 26,69 & 124,00 \\
\hline 3 & 13187,00 & 10088,02 & 23,50 & 1200,00 & 14007,00 & 27,98 & 120,00 \\
\hline 4 & 10425,00 & 8480,23 & 18,65 & 1200,00 & 12048,00 & 29,61 & 117,00 \\
\hline 5 & 22227,00 & 17846,89 & 19,71 & 1200,00 & 22345,00 & 20,13 & 124,00 \\
\hline 6 & 14293,00 & 10047,04 & 29,71 & 1200,00 & 16137,00 & 37,74 & 121,00 \\
\hline 7 & 12811,00 & 10061,33 & 21,46 & 1200,00 & 13333,00 & 24,54 & 123,00 \\
\hline 8 & 18197,00 & 13699,48 & 24,72 & 1200,00 & 18193,00 & 24,70 & 125,00 \\
\hline 9 & 18469,00 & 13802,39 & 25,27 & 1200,00 & 19519,00 & 29,29 & 123,00 \\
\hline 10 & 14573,00 & 11027,44 & 24,33 & 1200,00 & 15293,00 & 27,89 & 121,00 \\
\hline Média & & & 23,37 & 1200,00 & & 27,70 & 121,80 \\
\hline
\end{tabular}

Tabela 7.4: Solução dos problemas grandes. 


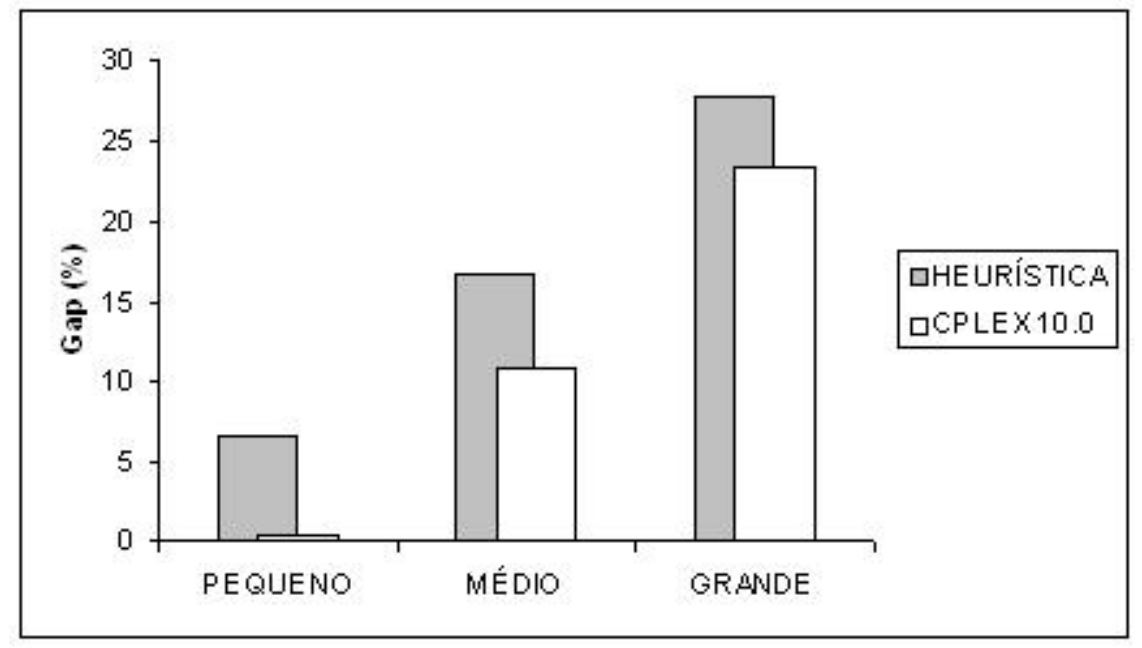

Figura 7.1: Qualidade da solução encontrada para os problemas pequenos, médios e grandes.

para 1 dos 10 problemas médios e 6 dos 10 problemas grandes o Cplex 7.5 não encontrou solução inteira factível nos 1200 segundos estabelecidos. Isto mostra que o pacote Cplex tem sido batante aprimorado. A despeito disto, heurísticas orientadas para um problema (como é a heurística proposta neste trabalho) podem ser bastante competitivas. Note que a vantagem do pacote Cplex diminui na medida que o tamanho do problema cresce. A superioridade de um método exato, bem implementado, é esperada para problemas pequenos. Os resultados apontam que a linha seguida na construção da heurística é promissora e pode ser melhorada.

Para analisar o comportamento dos métodos de solução em relação à quantidade de tipos de itens, foram gerados 5 novas classes de problemas. Estes problemas seguem os parâmetros definidos para o problema médio da Tabela 7.1, mas com diferente quantidade de tipos de itens, que são fixados em $N=25, N=50, N=75, N=100$ e $N=150$. Para cada uma destas novas classes foram gerados 10 problemas e analisados a qualidade da solução e o tempo computacional.

A Figura 7.2 mostra a qualidade da solução encontrada pelo método heurístico para as cinco novas classes e a Figura 7.3 o tempo computacional. Observa-se que quanto maior o número de itens definidos no problema, maior o valor do gap da solução e maior o tempo computacional. Neste caso, variando a quantidade de itens de 25 para 150, houve um acréscimo no gap em torno de 25\%. Já o tempo computacional aumenta consideravelmente com o acréscimo dos 25 itens de cada classe. 


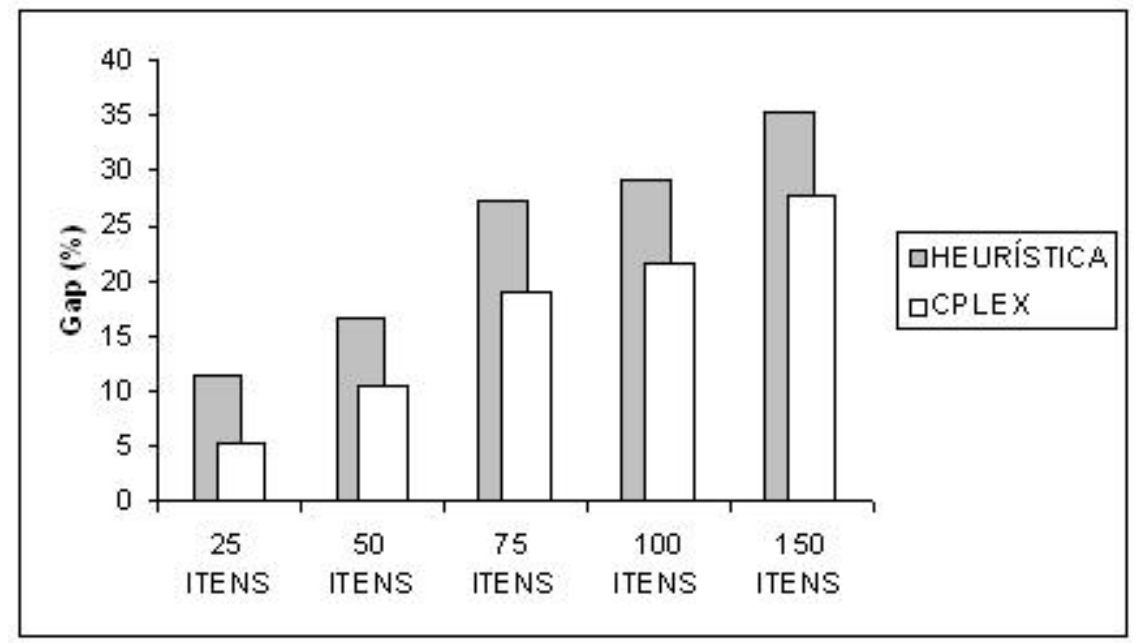

Figura 7.2: Qualidade da solução encontrada pelo método heurístico para os problemas com quantidade diferente de itens.

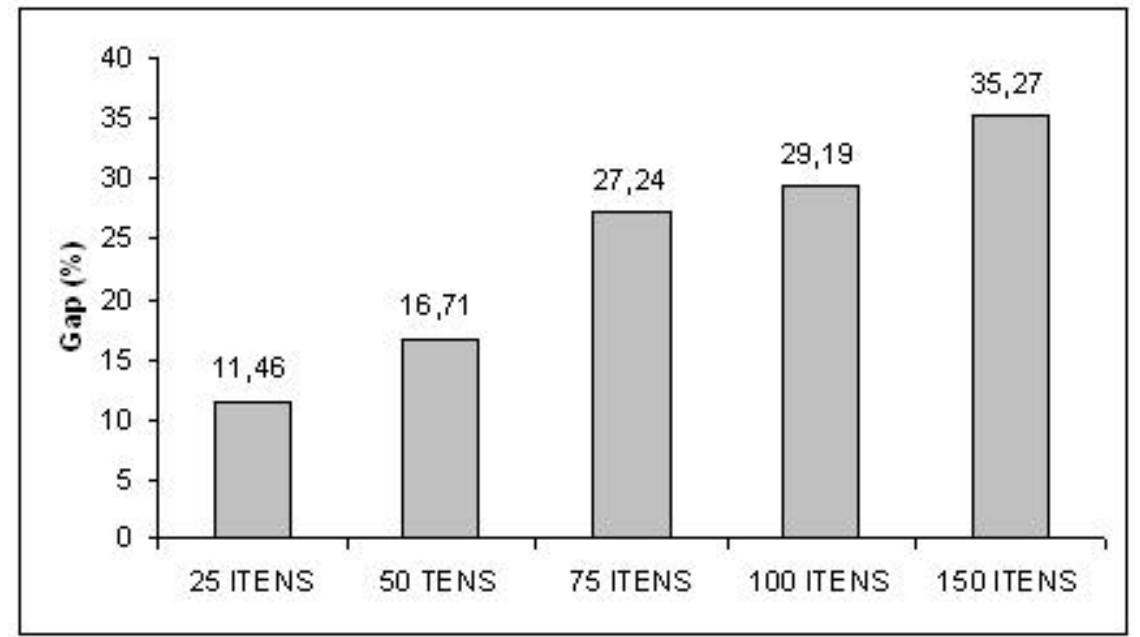

Figura 7.3: Tempo computacional do método heurístico para os problemas com quantidade diferente de itens. 


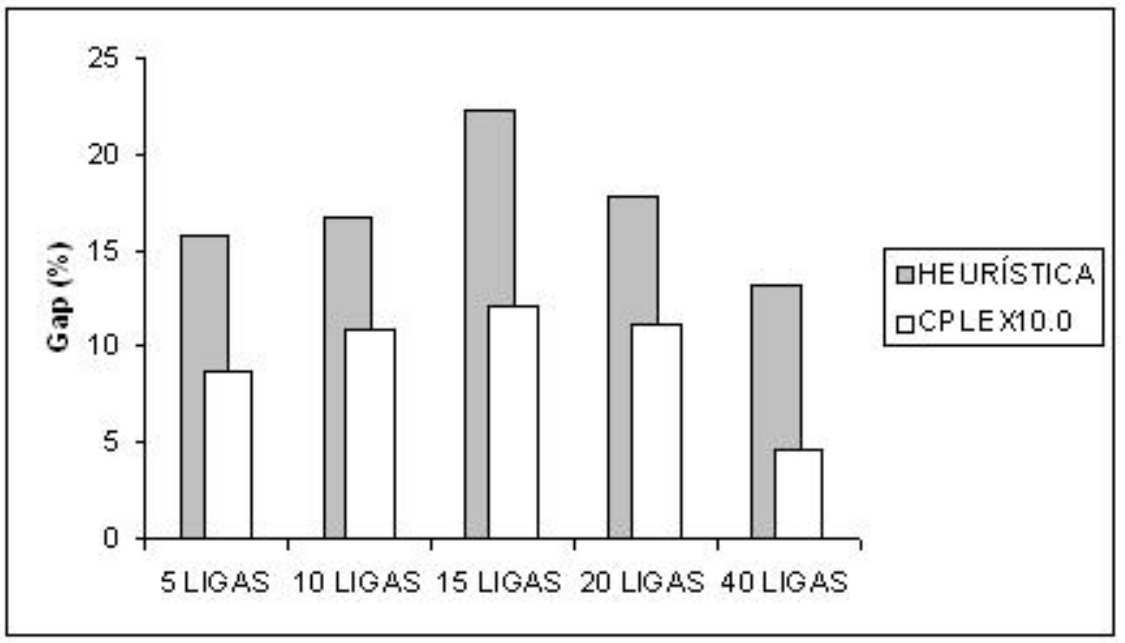

Figura 7.4: Qualidade da solução encontrada pelo método heurístico para os problemas com quantidade diferente de ligas.

De maneira análoga ao estudo realizado para observar o impacto da quantidade dos itens no problema, é feita uma análise em relação a quantidade de ligas. Fixando $K=5, K=10, K=15, K=20$ e $K=40$ no problema médio definido pelos parâmetros da Tabela 7.1, foram gerados 10 problemas para cada uma destas 5 classes.

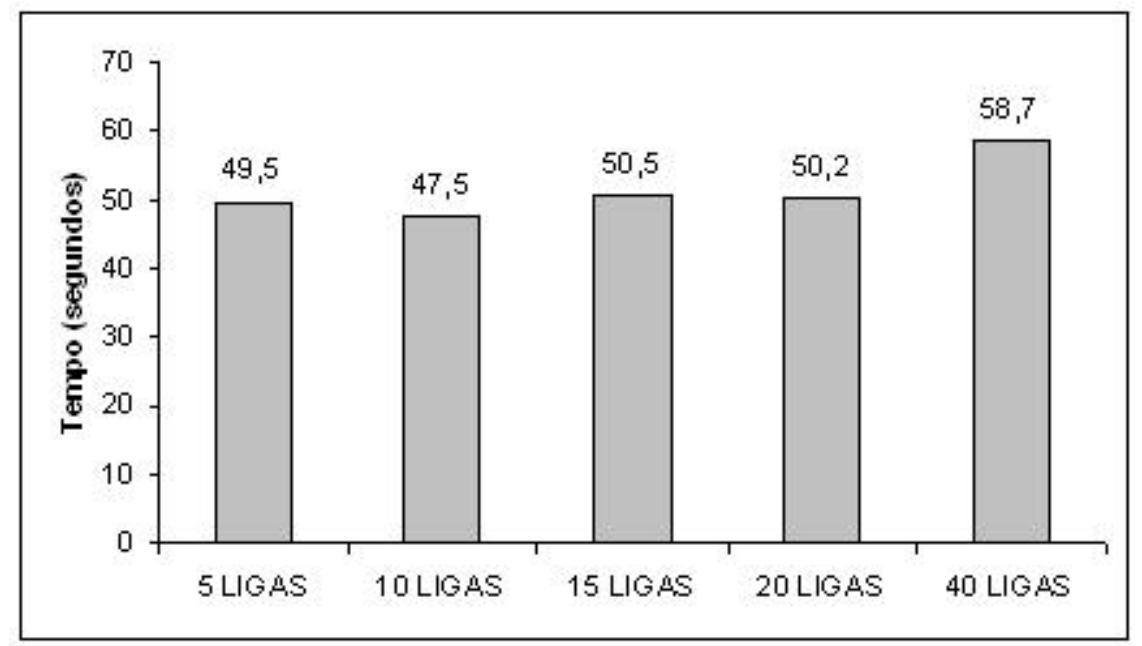

Figura 7.5: Tempo computacional do método heurístico para os problemas com quantidade diferente de ligas.

A qualidade da solução encontrada pelo método heurístico proposto é comparada com a solução encontrada pelo Cplex, conforme mostra a Figura 7.4, em que, os dois métodos formam uma curva semalhante no gráfico, mas com os resultados do Cplex 
sempre superiores ao método heurístico. O gap varia entre $13 \%$ e $23 \%$ para o método heurístico. A Figura 7.5 mostra a variação do tempo computacional entre 49,5 e 58,7 segundos, ou seja, um acréscimo de quase 10 segundos. Assim, tanto o gap quanto o tempo computacional resultantes não sofreram alterações expressivas com o acréscimo de ligas, considerando que a decisão de que liga produzir é bastante significativa na solução do problema e faz crescer o número de variáveis binárias.

Depois de analisado o comportamento do problema em relação aos itens e ligas, é feito um questionamento sobre o impacto da quantidade de demanda em atraso. Em todos os problemas gerados até agora, a quantidade (em $\mathrm{kg}$ ) de demanda atrasada era 20\%. Na sequência, são geradas cinco novas classes fixando esta quantidade de demanda em 10\%, 20\%, 30\%, 40\% e 80\%, no problema médio definido.

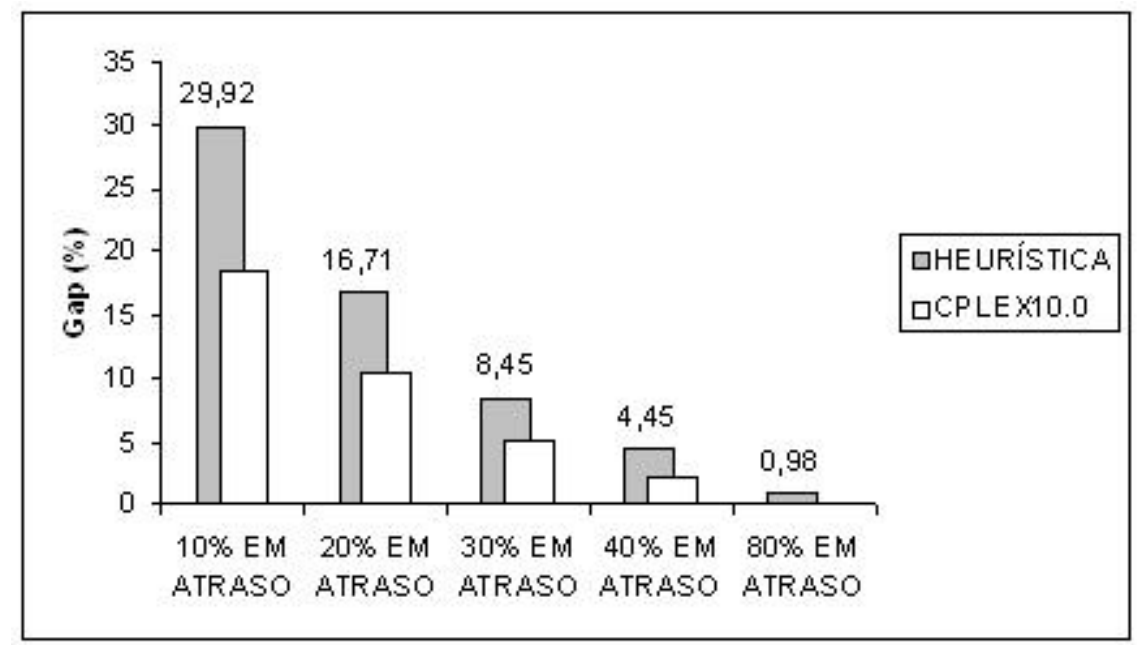

Figura 7.6: Qualidade da solução encontrada pelo método heurístico para os problemas com diferente quantidade de demanda atrasada.

As soluções encontradas, tanto pela heurística proposta, como pelo pacote Cplex, mostram que o comportamento do problema é melhor para os problemas com maior demanda atrasada, no caso, 80\%. A qualidade das soluções encontradas pela heurística estão representadas na Figura 7.6 e mostra a diminuição do gap da solução conforme aumenta a quantidade de demanda atrasada, enquanto o tempo computacional fica em torno de 50 segundos. Em certo sentido, o problema é mais bem resolvido quando a demanda em atraso é alta. 


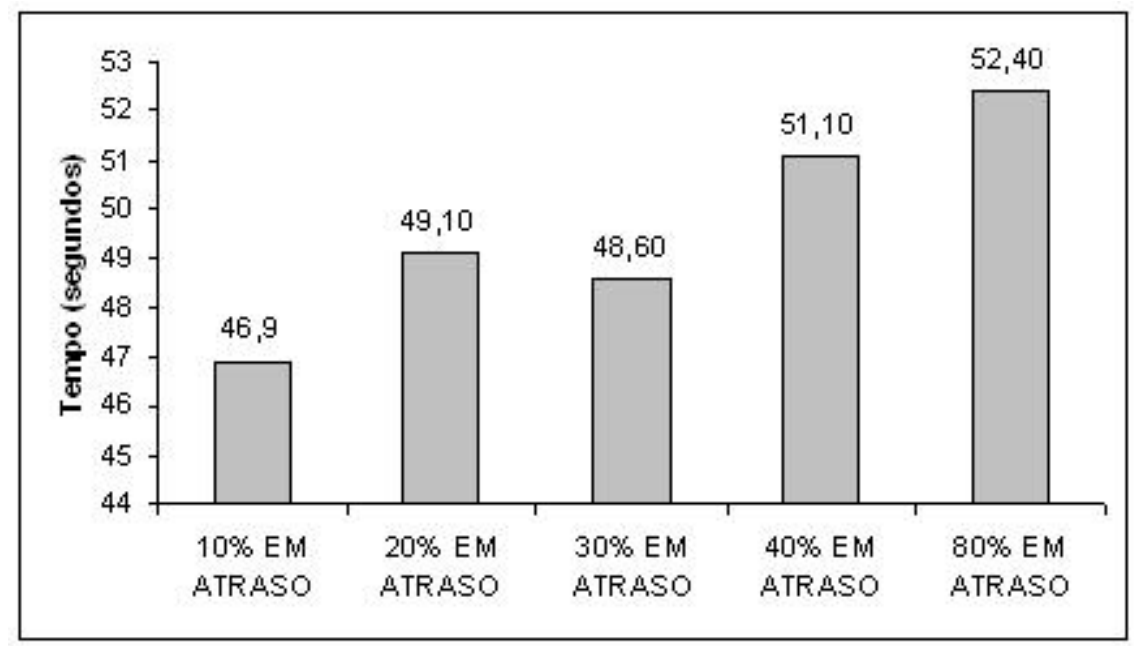

Figura 7.7: Tempo computacional do método heurístico para os problemas com diferente quantidade de demanda atrasada. 


\section{Capítulo 8}

\section{Conclusões e trabalhos futuros}

Neste trabalho foram analisados problemas de dimensionamento e sequenciamento de lotes capacitado, com múltiplos itens e horizonte de planejamento finito, com possibilidade de atraso no atendimento da demanda. O problema atende as características apresentadas numa fundição de pequeno porte e visa minimizar o atraso na entrega da demanda.

Este trabalho é baseado no problema estudado por Araújo (2003) e Tonaki (2006). O método de solução é iniciado aplicando uma estratégia de horizonte rolante no problema inteiro misto. Em seguida, aplica-se um método relaxe-e-fixe, em que as variáveis binárias são determinadas por busca local, enquanto outras variáveis inteiras são relaxadas, obtendo uma solução contínua infactível para o problema original. Para recuperar a integralidade destas variáveis é desenvolvida uma heurística residual, na qual, algumas variáveis são arredondadas gerando uma capacidade residual de máquina (forno), a qual é preenchida de forma gulosa, resolvendo-se problemas da mochila.

São definidos três tipos de problemas teste, os pequenos, os médios e os grandes. A qualidade da solução e o tempo computacional encontrados pelo método de solução proposto são comparados com os obtidos pelo pacote Cplex 10.0, este último com tempo limite fixado em 1200 segundos. O tempo computacional do método heurístico proposto é baixo, variando em torno de 13 segundos nos problemas pequenos e 2 minutos para os problemas definidos grandes. O pacote Cplex esgotou os 20 minutos antes da otimalidade.

Analisando a qualidade da solução, o desempenho da heurística proposta mostrouse inferior ao Cplex 10.0 em todos os casos, entretanto, a proporção entre os gaps da heurística e do Cplex diminuem consideravelmente quando se aumenta o tamanho do 
problema.

Mais testes computacionais são realizados com o intuito de observar o comportamento do problema quando fixadas diferentes quantidades de itens ou ligas.

O aumento da quantidade de itens definidos nos problemas testados, causa considerável acréscimo no gap e no tempo computacional encontrados pelo método heurístico proposto e pelo método Cplex. Ou seja, o número de itens é uma grandeza importante para definir o tamanho do problema.

São testados outros 5 casos de problemas, em que, são fixados diferentes quantidades de demanda atrasada no início da programação, em 10\%, 20\%, 30\%, 40\% e 80\%. O gap da solução declina para a heurística proposta, de 29,92\% (quando a demanda atrasada é definida em 10\%), chegando a $0,98 \%$, no caso em que a demanda atrasada é definida em $80 \%$. Nestes testes, o tempo variou entre 46,9 e 52,4 segundos. O pacote Cplex teve comportamento similiar.

Foi observado durante os testes computacionais que, a busca local é que mais consome tempo e, portanto, podem ser testadas outras maneiras para obter as variáveis binárias. Uma sugestão é aplicar o problema de planejamento das ligas desenvolvido por Tonaki (2006), conforme mostrado no capítulo 3. Ou seja, um investimento maior para a fixação inicial das ligas.

Na literatura são apresentadas várias técnicas de arredondamento, como por exemplo, as de Poldi (2003) e de Maes et al. (1991), que podem melhorar o comportamento do método de solução. Por exemplo, o truncamento dos valores fracionários pode ser revisto e heurísticas mais elaboradas que permitam arredondar algumas variáveis para o inteiro superior podem ser investigadas.

Para o aproveitamento da capacidade residual gerada em cada subperíodo é resolvido um problema da mochila com itens definidos a priori. Na heurística proposta, nos limitamos a itens em atraso no primeiro dia. Outros critérios para definir estes itens poderiam ser investigados, como por exemplo, antecipar para o primeiro dia a produção de itens que apresentam atrasos no período seguinte. 


\section{Bibliografia}

[1] ABIFA - Associação Brasileira de Fundição. http://www.abifa.org.br (2007).

[2] Araújo, S. A., Arenales, M. N. e Clark, A. R (2006), Lot-sizing and furnace schedulling in small market-driven foundries. Aceito na Computers \& Operations Research.

[3] Araújo, S. A. e Arenales, M. N. (2003a), Dimensionamento de lotes e programação do forno numa fundição automatizada de porte médio. Pesquisa Operacional, v.23, n.3, p.403-420.

[4] Araújo, S. A.(2003), Modelos e métodos para o planejamento e programação da produção aplicados no setor de fundições. Tese de Doutorado, ICMC-USP.

[5] Araújo, S. A., Arenales, M. N. (2000), Problema de dimensionamento de lotes monoestágio com restrição de capacidade: modelagem, método de resolução e resultados computacionais, Pesquisa Operacional, v.20, n.2, p.455-464.

[6] Brahimi, N., Dauzere-Perez, S., Najid,N. M., Nordli, A.(2006), Single item lot sizing problems, European Journal of Operational Research, v.168, p.1-16.

[7] Clark, A. R., Clark, S. J.(2000), Rolling-Horizon Lot-Sizing When Setup Times are Sequence-Dependent, International Journal of Production Research, v.38, n.10, p.22872307.

[8] Diaby, M., Bahl, H., Karwan, M. H.,Ziont, S.(1992), Capacitate Lot-Sizing and Scheduling by Lagrangean Relaxation, European Journal of Operational Research, v.59, p.444-458. 
[9] Fernandes, F. C. F., Leite, R. B.(2002), Automação Industrial e Sistemas Informatizados de Gestão de Produção em Fundições de Mercado, Gestão e Produção, v.9, n.3, p.313-344.

[10] Florian M., Lenstra J. K. e Rinnoy Kan, A. H. G. (1980), Deterministic Production Planning Algorithms and Complexity, Management Science, v.26, n.7, p.669-679.

[11] Harris, F. W. (1913), How many parts to make at once, The Magazine of Management, v.10, p.135-136.

[12] Karimi, B., Fatemi Ghomi, S.M.T. e Wilson, J.M. (2003), The capacitated lot sizing problem: a review of models and algorithms, OMEGA, v.31, p.365-378.

[13] Maes J., McClain, J. O. e van Wassenhove, L. N. (1991), Multilevel capacitated lotsizing complexity and LP based heuristic, European Journal of Operational Research, v.53, p.131148.

[14] Poldi, K. C.(2003), Algumas extensões do problema de corte de estoque. Dissertação de Mestrado, ICMC-USP.

[15] Santos, M. O. (2000), Problemas de Dimensionamento de Lotes: Modelos e Métodos, Tese de Doutorado, ICMS-USP/SC.

[16] Santos-Meza, E., Santos, M. O., Arenales, M. N. (2001), A Lot-Sizing Problem in an Automated Foundry, European Journal of Operational Research, v.139, n.2, p.490-500.

[17] Silva, R. J.(2001), Programação de Cargas de Forno em uma Fundição de Mercado, Dissertação de Mestrado, Departamento de Engenharia de Produção, UFSCar.

[18] Toledo, F. M. B., Armentano, V. A., França, P. M. (1994), Um Método Ótimo para o Problema de Dimensionamento de Lotes com Restrições de Capacidade, SBPO. 
[19] Tonaki, V. S.(2006), Uma heurística para o problema de dimensionamento de lotes em fundições de mercado. Dissertação de Mestrado ICMS-USP/SC.

[20] Trigeiro W. W., Thomas L. J. e McClain J. O. (1989), Capacitated Lot Sizing With Setup Times, Management Science, v.35, n.3, p.353-366.

[21] Wagner, H. M., Whitin, T. M. (1958), Dynamic Version of the Economic Lot Size Model, Management Science, v.5, n.1, p.89-96.

[22] Wolsey, L. A., (1998), Integer Programming, Wiley, New York. 